DR. ALLISON M MCKENDRICK (Orcid ID : 0000-0003-1972-1222)

DR. LAURA ELIZABETH DOWNIE (Orcid ID : 0000-0002-1596-2259)

Article type : Original Article

$$
\square
$$

\title{
Clinical audit as an educative tool for optometrists: an intervention study in
} age-related macular degeneration

Running head: Clinical audit: an educative tool for optometrists

Sena A Gocuk, ${ }^{1}$ Ji-hyun Lee, ${ }^{1}$ Peter R Keller, ${ }^{1}$ Lauren N Ayton, ${ }^{1,2,3}$ Robyn H Guymer, ${ }^{2,3}$ Allison M McKendrick, ${ }^{1}$ Laura E Downie ${ }^{1}$

${ }^{1}$ Department of Optometry and Vision Sciences, The University of Melbourne, Parkville, Victoria, Australia; ${ }^{2}$ Department of Surgery (Ophthalmology), The University of Melbourne, Parkville, Victoria, Australia; ${ }^{3}$ Centre for Eye Research Australia, Royal Victorian Eye and Ear Hospital, Melbourne, Victoria Australia.

\section{Word count: 5,553}

Keywords: clinical audit, optometry, age-related macular degeneration, clinical record

\section{Corresponding author:}

A/Prof Laura Downie

Department of Optometry and Vision Sciences

Faculty of Medicine, Dentistry and Health Sciences

The University of Melbourne, Carlton VIC Australia 3053

P +61 39035 3043, E Idownie@unimelb.edu.au

\section{Abstract}

This is the author manuscript accepted for publication and has undergone full peer review but has not been through the copyediting, typesetting, pagination and proofreading process, which may lead to differences between this version and the Version of Record. Please cite this article as doi: $10.1111 / 0 P 0.12754$

This article is protected by copyright. All rights reserved 
Purpose: Age-related macular degeneration (AMD) is a major cause of vision loss. This study investigated whether performing clinical audit and receiving analytical performance feedback altered documentation of the AMD care provided by optometrists.

Methods: Australian optometrists were recruited and completed a survey about their demographics and confidence in AMD care, and a three-month audit of their practice records using an AMD audit tool (termed the pre-audit evaluation). After receiving analytical feedback, participants identified areas for improvement and re-audited their practices after three months to analyse changes in performance (termed the post-audit evaluation). Paired t-tests and Wilcoxon signed-rank tests, as appropriate, were used to compare pre- and postaudit data.

Results: Twenty optometrists, most practising in Victoria, Australia, completed the study. Participants primarily worked in corporate practice and/or rural settings and had a range of optometric experience (2-40 years). At baseline, participants felt confident in their: knowledge of AMD risk factors (65\%), advice to patients about these factors (55\%) and management of earlier stages of AMD (55\%). Each clinician completed (median [IQR]): 15 [IQR: 10-19] and 12 [IQR: 8-16] audits of unique patient records, pre- and post-audit, respectively. Post-audit, average record documentation (per optometrist) improved for asking about: AMD family history ( $94 \%$ to $100 \%, p=0.03$ ), smoking status ( $21 \%$ to $58 \%, p<$ $0.01)$, diet $(11 \%$ to $29 \%, p<0.01)$ and nutritional supplementation $(20 \%$ to $51 \%, p<0.01)$. For clinical examination, compliance with documenting pinhole visual acuity, performing an in-office Amsler grid (upon indication) and using optical coherence tomography improved post-audit $(p<0.05)$. Accuracy of severity documentation improved for earlier stages of AMD $(p<0.05)$. For earlier stages of AMD, documentation of counselling about modifiable risk factors significantly improved post-audit $(p<0.05)$. Aspects well-performed pre-audit that did not change included documenting: medical histories $(100 \%$ at both time points, $p=$ $0.06)$ and retinal imaging ( $77 \%$ at both time points, $p=0.97)$.

Conclusions: Self-audit with analytical feedback improved clinical record documentation of: AMD risk factors, clinical examination, AMD severity classification and management advice. These findings support a role for audit to improve optometric clinical care of AMD, as evidenced by improved documentation of the AMD care delivered.

\section{Introduction}

This article is protected by copyright. All rights reserved 
Age-related macular degeneration (AMD) is a degenerative condition of the macula that affects individuals over the age of 55 years. It is the leading cause of irreversible vision impairment among adults in developed countries. ${ }^{1,2}$ Currently, there are only approved medical therapies for the late neovascular form of the condition, primarily with intra-vitreal anti-vascular endothelial growth factor (anti-VEGF) agents. ${ }^{3,4}$ There are currently no validated treatments for earlier stages of AMD or the atrophic late-stage form. ${ }^{5}$ Reducing the risk of progression to late-stage AMD through modifying key lifestyle risk factors and nutritional supplementation (where appropriate) are important approaches for reducing vision loss from AMD. ${ }^{3,6}$

In Australia, optometrists are major providers of primary eye care, including for AMD. Optometrists are thus ideally placed to counsel their patients about modifiable factors that can affect $A M D$ development and progression. To achieve this, optometrists need to accurately identify AMD and classify its severity ${ }^{3,6}$ using an accepted disease classification. The use of common nomenclature facilitates accurate record keeping and appropriate communication between clinicians, ${ }^{1}$ and the Beckman Initiative for Macular Disease Classification system (2013) is an established AMD classification system. ${ }^{1}$ This classification system (Table 1) relies upon clinically-identified (or colour fundus photography-defined) characteristics located within two-disc diameters of the fovea, and redefined key terms relating to AMD severity in adults aged over 55 years. ${ }^{1,7}$

Several factors increase an individual's risk of developing AMD. Age, ${ }^{8-10}$ ethnicity ${ }^{8,9,11}$ and family history of $A M D^{8,9,12}$ are the main non-modifiable risk factors. Smoking is the most important modifiable risk factor. ${ }^{10,13,14}$ Smoking imparts a two-to three-fold increase in the risk of developing AMD and progressing to later stages of disease, particularly choroidal neovascularisation (CNV). 8,15,16 While former smokers are still at risk of developing AMD compared to non-smokers, ${ }^{15-17}$ after 20 years of smoking cessation the risk of AMD reduces to that of someone who has never smoked. ${ }^{15,18,19}$

Dietary factors have also been linked to AMD risk. Diets dominated by high glycaemic index (GI) relative to low-GI foods, ${ }^{20}$ high omega- 6 relative to omega- 3 fatty acid intake, ${ }^{21}$ low dairy and calcium ${ }^{22}$ and high red meat consumption ${ }^{23}$ have been associated with an 
increased risk of late AMD. A Mediterranean diet, involving high consumption of vegetables, fruit, legumes, whole grains and nuts; moderate consumption of fish, poultry and dairy; use of olive oil and limited red meat consumption may reduce both the incidence and progression of AMD. ${ }^{24-26}$ Specific types of nutritional supplementation may reduce the risk of progression to late $A M D$ in individuals with signs of at least intermediate $A M D^{27,28}$ (interpreted in the context of the Beckman classification ${ }^{1}$ ). The Age-Related Eye Disease Study (AREDS) found that a specific formulation of high-dose antioxidant and mineral supplements reduced the absolute risk of progression to late-stage AMD from $28 \%$ to $20 \%$ at 5 years in certain high risk sub-types of AMD. ${ }^{28}$

It is therefore crucial that optometrists provide appropriate advice to their patients about AMD risk modification. A 2015 survey exploring the practices of Australian optometrists found scope for improving clinician screening and counselling about modifiable AMD risk factors. ${ }^{29}$ However, these findings were based on the self-reported behaviours of optometrists, which can be affected by recall bias. There is thus an opportunity to further investigate optometric practice patterns by objectively evaluating historic patient records, as a means for gaining insight into the clinical care provided to patients. ${ }^{30}$ The World Health Organization describes patient records as medical documents that can be used to assess the quality of care. ${ }^{31}$ Inaccurate or incomplete records may negatively impact the quality of patient care and have legal ramifications. ${ }^{31}$ Examining records using clinical audit aims to provide a measure of the quality of patient care, and to encourage clinicians to follow professional standards. ${ }^{32}$

The National Institute for Clinical Excellence defines clinical audit as "a quality improvement process that seeks to improve patient care and outcomes through systematic review of care against explicit standards and the implementation of change". ${ }^{33}$ As the final step of the evidence-based practice cycle, clinical audit is recognised to be a key component of quality healthcare delivery. ${ }^{34,35}$ In Australia, there are currently no national clinical guidelines, from the National Health and Medical Research Council (NHMRC), for AMD. In the context of AMD care provision in Australia, auditing patient records against current best-practice standards will provide insight into whether optometrists are documenting care consistent with the recommendations in the Royal Australian and New Zealand College of 
Ophthalmologists (RANZCO) AMD referral pathway. ${ }^{36}$ A recent study measuring the appropriateness of delivery of preventative glaucoma and diabetic eye care in Australia reported low compliance with documenting history taking and clinical examination techniques compared to evidence-based guidelines. ${ }^{37}$ Other clinical audit studies, undertaken in the United Kingdom (UK), have analysed optometric practice patterns and management in low vision ${ }^{38}$ and glaucoma clinics. ${ }^{39}$ However, currently no studies have analysed the optometric care provided to people with, or at risk of, AMD.

The primary aim of this study was to investigate whether performing clinical self-audit and receiving analytical feedback improved clinical record documentation, as a proxy for AMD care, provided by a group of Australian optometrists. It was hypothesised that the process of self-audit and receipt of quantitative feedback would improve the documentation (and thus clinical care) with respect to AMD risk factors, use of diagnostic imaging modalities, AMD severity classification and management.

\section{Methods}

This project was conducted in accordance with the 2018 NHMRC National Statement on Ethical Conduct in Human Research and received approval from the University of Melbourne Human Research Ethics Committee (Ethics ID: 1851607). All participants provided written informed consent to participate.

\section{Participant recruitment and eligibility}

The study was promoted to optometrists at two major Australian clinical education conferences (Southern Regional Congress, Melbourne, May 26-27 2018 and the Western Australian Vision Education meeting, Perth 11-12 August 2018). Two researchers (LED, J-HL) hired a booth in the trade exhibition at both conferences which enabled optometrists to register their interest to participate. The study was also advertised in various resources distributed to the Australian eye care community, including professional magazines and email correspondence. 
To be eligible to participate, optometrists were required to be currently practising in Australia, routinely managing patients with, or at risk of, developing AMD and have access to their own written or electronic clinical records. Data were collected between March 2018 and August 2019.

\section{Study design}

Following provision of written informed consent, participants completed a hard-copy baseline survey to capture their demographics, AMD practice patterns and confidence in their knowledge and management of AMD. Information captured by the survey included:

1. Participant demographics: gender; location of completing their optometry degree; year of graduation; whether they had therapeutic endorsement to prescribe scheduled medicines (yes/no); average clinical hours worked per week; principal practice setting (e.g., academic, corporate practice, hospital clinic, public health clinic, private practice, refractive surgery clinic etc.), and practice location (postcode).

2. Practice patterns relating to AMD: estimated average number of AMD patients seen per week; AMD grading scale used (if any); AMD clinical guidelines used (if any),and imaging devices available at their practice.

3. Confidence in AMD practice, on a five-step Likert scale ranging from not at all confident to very confident, for: knowledge of risk factors for developing AMD; knowledge of risk factors for AMD progression; asking patients about modifiable risk factors for developing AMD; providing advice to patients about modifiable risk factors for developing AMD; providing advice to patients about modifiable risk factors for AMD progression; diagnosing earlier stages of AMD; managing earlier stages of AMD and ability to appropriately refer AMD patients for medical retinal sub-specialist care.

Participants were then asked to audit their clinical records for patients with, or at risk of, AMD, using the Macular Degeneration Clinical Care Audit Tool (MaD-CCAT) (Figure 1, described in detail below), developed by the authorship team. The audit considered patients seen in the three-month period prior to the optometrists' enrolment in the study. A patient 
'at risk' of AMD was defined as an individual with a family history of AMD and aged 50 years or older.

After completing the three-month initial audit (termed the 'pre-audit' evaluation time point), participants accessed quantitative analytical data summarising the relative 'compliance' of their clinical record keeping relative to current best-practice (as defined in the MaD-CCAT). The analytical data were automatically generated in the MaD-CCAT based on the optometrists' responses to the audit questions. For each item in the MaD-CCAT, participants received a percentage score that summarised their overall level of compliance for that item across all audits performed. The analytical data also included an output that summarised the individual audit items with the highest levels of non-compliance (i.e., the areas of weakest performance). Using this information, participants self-identified five key areas to focus on for self-improvement and emailed this list to the researchers. The researchers provided the option for participants to receive relevant research papers on the topic(s) of their self-nominated areas but did not provide any additional education or support to assist them with modifying their practice behaviours.

After another three months, participants re-audited their practices using the MaD-CCAT for a subsequent set of patients. The evaluation at the end of this period is termed the 'postaudit' time point. Once the post-audit was completed, participants were emailed a link to a final survey, which captured their confidence in AMD knowledge and practice after study participation, using the same questions as the baseline survey. Participants were also asked to indicate their level of agreement, using a five-step Likert scale that ranged from strongly disagree to strongly agree, for aspects relating to their perceived value and utility of both the MaD-CCAT tool and clinical audit in optometry practice.

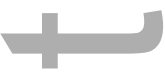

\section{Macular Degeneration Clinical Care Audit Tool (MaD-CCAT)}

The MaD-CCAT for auditing optometric practice for patients with, or at risk of, AMD was developed by the research team using iAuditor by SafetyCulture (www.safetyculture.com). The MaD-CCAT assesses: documentation of risk factors for AMD development and/or progression; the use and appropriateness of diagnostic tests to provide a comprehensive assessment of disease severity; documentation of patient management; the accuracy of ophthalmology referrals, and recommended review periods (Figure 1).

This article is protected by copyright. All rights reserved 
The sequence of questions was carefully mapped out to investigate the management of individual patients, as informed by 'The Royal Australian and New Zealand College of Ophthalmologists (RANZCO) referral pathway for AMD screening and management by optometrists' (2018). ${ }^{36}$ This resource describes the screening and management advice for patients with AMD depending on disease severity, including recommended review periods and when to refer for ophthalmological care.
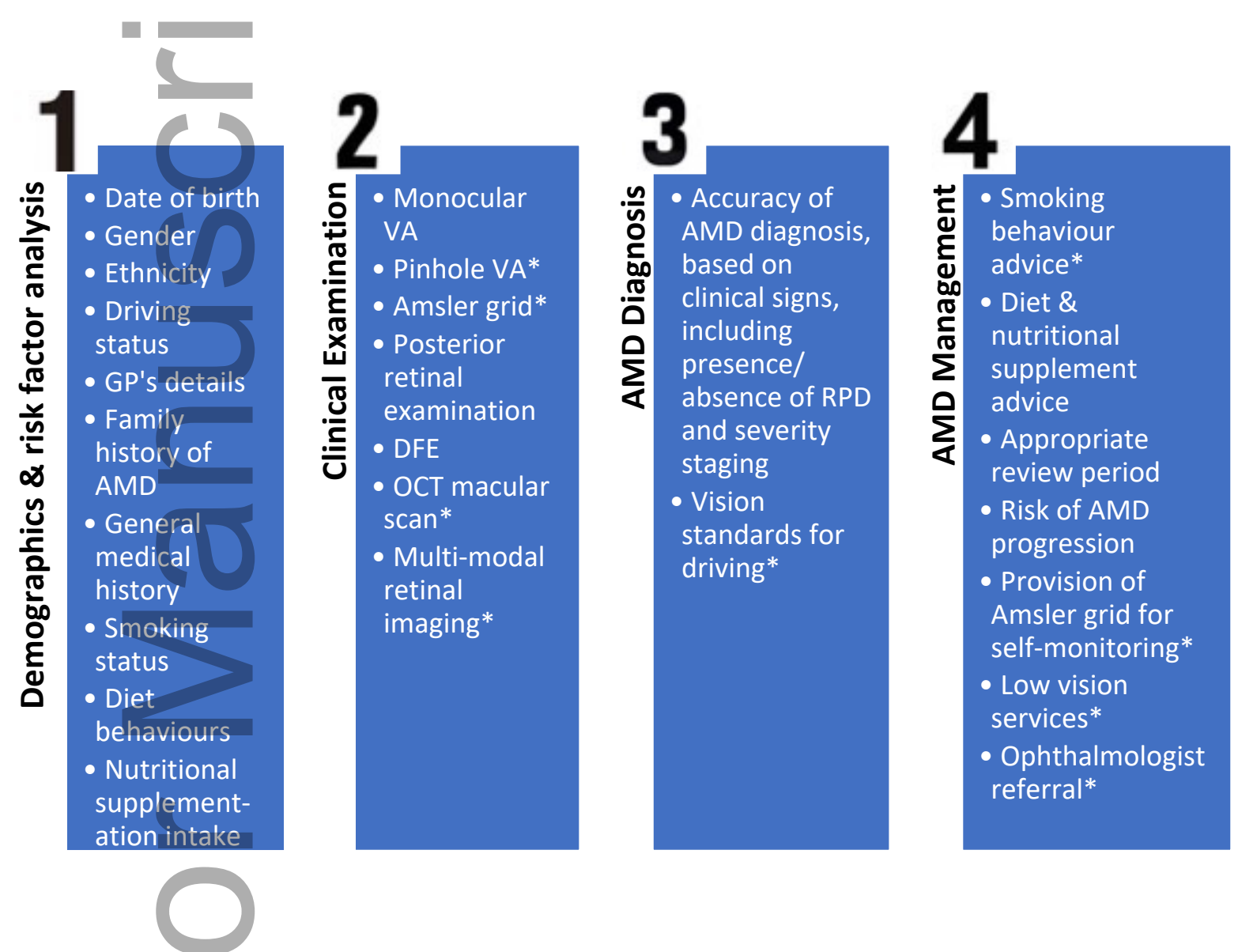

Figure 1. Areas of clinical record keeping assessed by the Macular Degeneration Clinical Care Audit Tool (MaD-CCAT). 'Diet behaviours' related to dietary behaviours specifically relevant to AMD; *when clinically indicated for a given patient.

$A M D$, age-related macular degeneration; DFE, dilated (retinal) fundus examination; GP, general practitioner; $O C T$, optical coherence tomography; VA, visual acuity 
Most questions in the MaD-CCAT required a yes/no/not applicable response. Participants were directed to select their responses based only on what was documented on their clinical records. A MaD-CCAT supporting instruction manual was provided for reference. The MaD-CCAT audits four main clinical areas:

1. Patient demographics and risk factors. Participants indicated whether they documented: patient date of birth; gender; ethnicity; current motor vehicle driving status; general practitioner (GP) details; comprehensive general medical history; family history of AMD; current smoking status; current dietary behaviours relevant to $\mathrm{AMD}$ and nutritional supplement intake.

2. Clinical examination. Participants noted whether monocular best corrected visual acuities (BCVA), monocular pinhole acuities (when applicable), and monocular Amsler grid test (when applicable) were recorded. Monocular pinhole acuities and an Amsler grid test were considered 'not applicable' except when there was a clinical indication, such as reduced BCVA or clinical symptoms or signs of AMD, respectively. Participants were also required to indicate whether a bilateral posterior ocular examination, dilated retinal fundus examination, and stereoscopic examination were performed. If retinal imaging was performed, participants were asked to indicate whether retinal fundus photography, optical coherence tomography (OCT) macular raster scan (when indicated) and/or multimodal imaging such as infrared imaging (IR) or fundus autofluorescence (FAF) (when indicated) were performed. Participants

Table 1. Beckman Initiative for Macular Disease Classification System (2013) ${ }^{\dagger}$

${ }^{\dagger}$ Definition is based on the worst eye and for lesions assessed within two-disc diameters of the fovea.

${ }^{\ddagger}$ AMD pigmentary abnormalities are hypo- or hyper-pigmentation associated with presence of drusen $>63 \mu \mathrm{m}$. AMD: Age-related macular degeneration

\begin{tabular}{|c|c|}
\hline No ageing changes & No drusen or AMD pigmentary abnormalities ${ }^{\ddagger}$ \\
\hline $\begin{array}{l}\text { Normal ageing } \\
\text { changes }\end{array}$ & $\begin{array}{l}\text { Small drusen ( } \leq 63 \mu \mathrm{m} \text { at their smallest diameter) and no pigmentary } \\
\text { abnormalities }^{\ddagger}\end{array}$ \\
\hline Early AMD & $\begin{array}{l}\text { Medium drusen (>63 } \mu \mathrm{m} \text { and } \leq 125 \mu \mathrm{m} \text { ) and no AMD pigmentary } \\
\text { abnormalities }^{\ddagger}\end{array}$ \\
\hline Intermediate AMD & Large drusen $(>125 \mu \mathrm{m})$ and/or any AMD pigmentary changes ${ }^{\ddagger}$ \\
\hline Late AMD & Neovascular AMD or geographic atrophy \\
\hline
\end{tabular}

This article is protected by copyright. All rights reserved 
selected 'not applicable' for OCT and multimodal imaging when there were no AMD risk factors or clinical signs of AMD present.

3. AMD diagnosis. Once the participant selected the clinical signs documented on the clinical record, the MaD-CCAT provided an AMD severity classification according to the Beckman Initiative for Macular Disease Classification system (2013). ${ }^{1}$ Participants then indicated whether this diagnosis matched the severity stage documented on their clinical records. Participants noted whether other features of neovascular AMD were detected such as intraretinal cysts that are an accumulation of fluid in the neurosensory retina and appear as hypo-reflective areas on $\mathrm{OCT}, 40$ or subretinal fluid that also appear on OCT as hypo-reflective spaces of fluid, between the neurosensory retina and retinal pigment epithelium (RPE). ${ }^{40}$ Participants also indicated whether they had assessed for the presence of reticular pseudodrusen (RPD), which are subretinal drusenoid deposits located above the RPE, typically located in the superior outer macula. RPD may increase an individual's risk of progression to late-stage $A M D,{ }^{41}$ although there is a need for a sufficiently large longitudinal study to more clearly define the relationship..$^{42}$

4. AMD management. Based on the AMD severity of the most advanced eye, this section considered how the patient was managed with respect to clinical discussions around current smoking behaviours, diet behaviours, nutritional supplementation, risk of AMD progression (for a patient with at least early AMD), Amsler grid provision and accurate instructions for home monitoring (for a patient with at least early AMD), and the nomination of an appropriate review period.

\section{Statistical analysis}

Statistical analyses were performed using GraphPad Prism (Version 7.0 for Windows, GraphPad Software, www.graphpad.com). Descriptive statistics were used to summarise the survey responses for clinician demographics, practice patterns and confidence in AMD care. The Shapiro-Wilk test was used to determine whether the data met the underlying assumption for parametric statistics of an approximately normal distribution. A student's paired t-test for parametric variables, or Wilcoxon test for non-parametric variables, was 
used to compare pre- and post-audit data. An alpha value of 0.05 was used to define statistical significance.

Participants' demographic information are presented as the total number of participants or median \pm interquartile range (IQR), as applicable. For each participant, the level of compliance was calculated based on the average value of compliance from multiple audited clinical records to represent overall performance. Audit outcomes for level of compliance graphs are represented using bars and error bars to show mean and $95 \%$ confidence intervals, respectively, for parametric variables. Box and whisker plots are used to show median and interquartile ranges, respectively, for non-parametric variables.

\section{Results}

\section{Participant characteristics}

Fifty optometrists provided informed consent to participate. Of these, 30 withdrew from the study (25 prior to completing any study-related tasks, and five after undertaking some preaudits). The reasons cited were: time commitment concerns ( $n=11)$, locum optometrists not able to access their clinical records $(n=3)$, insufficient AMD patients managed $(n=2)$, change in practice location $(n=2)$ and personal reasons $(n=2)$. Four participants were lost to follow up, and for six participants the reason was unspecified. In total, 20 participants completed the study; their baseline demographics and practice patterns are summarised in Table 2. Most participants were rurally based, had completed their optometry training in Australia, were endorsed to prescribe scheduled topical medications and practised in a corporate setting.

\section{Participants' confidence in AMD knowledge and care provision}

Participants rated their level of confidence in AMD knowledge and clinical care, on a scale from "not at all confident" to "very confident" (Figure 2). Data are shown for the 15 participants (75\% of total population) who completed both the pre- and post-audit surveys. At baseline, respondents felt most confident with managing earlier stages of AMD and referring patients for medical sub-specialist care, when appropriate. After self-audit, the areas that showed most improvement in confidence were: knowledge of risk factors for 
AMD development and progression, asking patients about these risk factors and diagnosing earlier stages of AMD.

Table 2. Baseline participant demographics and self-reported practice patterns n, number of participants; AMD, age-related macular degeneration; AREDS, Age Related Eye Disease Study; IQR, interquartile range; RANZCO, The Royal Australian and New Zealand College of Ophthalmologists

${ }^{\dagger}$ Two participants reported using two AMD grading scales

"Other AMD grading scales used were "clinical classification of AMD" and "Wisconsin ARM grading"

$\S$ These categories reflect the responses of participants who were asked whether they currently use an AMD guideline; we note that AREDS and the Macular Disease Foundation documents do not actually constitute clinical guidelines, by definition.

\begin{tabular}{|c|c|}
\hline 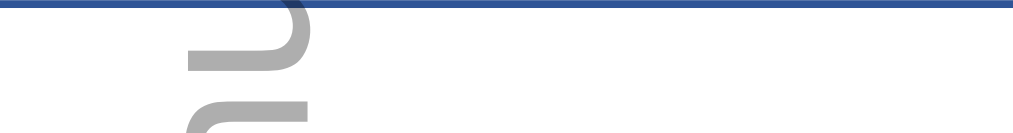 & $\begin{array}{l}\text { Respondents } \\
\qquad(n=20)\end{array}$ \\
\hline Gender, male: $n(\%)$ & $10(50)$ \\
\hline Degree completed in Australia: $\mathrm{n}(\%)$ & $19(95)$ \\
\hline Years since graduation: median; IQR & $8 ; 14$ [range: $2-40$ ] \\
\hline Therapeutically endorsed: $n(\%)$ & $18(90)$ \\
\hline Average clinical hours worked per week: median; IQR & $36 ; 9$ [range: $17-45$ ] \\
\hline $\begin{array}{l}\text { Principal place of practice: } \mathrm{n}(\%) \\
\text { - } \quad \text { Corporate } \\
\text { - } \text { Private }\end{array}$ & $\begin{array}{l}13(65) \\
7(35)\end{array}$ \\
\hline $\begin{array}{l}\text { Practice setting: } n(\%) \\
\text { - Metropolitan } \\
\text { - Rural }\end{array}$ & $\begin{array}{l}7(35) \\
13(65)\end{array}$ \\
\hline Average number of AMD patients seen per week: median; IQR & 3; 3 [range: $1-15$ ] \\
\hline $\begin{array}{l}\text { Use of an AMD grading scale }{ }^{\dagger}: \mathrm{n}(\%) \\
\text { - Beckman classification } \\
\text { - } \text { AREDS } \\
\text { - Other } \\
\text { - Unspecified }\end{array}$ & $\begin{array}{c}11(55) \\
5 \\
4 \\
2 \\
2\end{array}$ \\
\hline $\begin{array}{l}\text { Use of an AMD guideline: } \mathrm{n}(\%) \\
\text { - } \quad \text { RANZCO AMD referral pathway } \\
\text { - } \text { AREDS }^{\S}\end{array}$ & $\begin{array}{c}8(40) \\
1 \\
4\end{array}$ \\
\hline
\end{tabular}

This article is protected by copyright. All rights reserved 


\begin{tabular}{|c|c|}
\hline - Macular Disease Foundation $^{\S}$ & 3 \\
\hline Imaging devices available at practice: $\mathrm{n}(\%)$ & $18(90)$ \\
- Fundus photography & $13(65)$ \\
- Optical coherence tomography & $9(45)$ \\
- Fundus autofluorescence & $5(25)$ \\
- Daytona Optos & $1(5)$ \\
- Infrared imaging & \\
\hline
\end{tabular}

Participants' confidence in AMD knowledge and clinical care provision

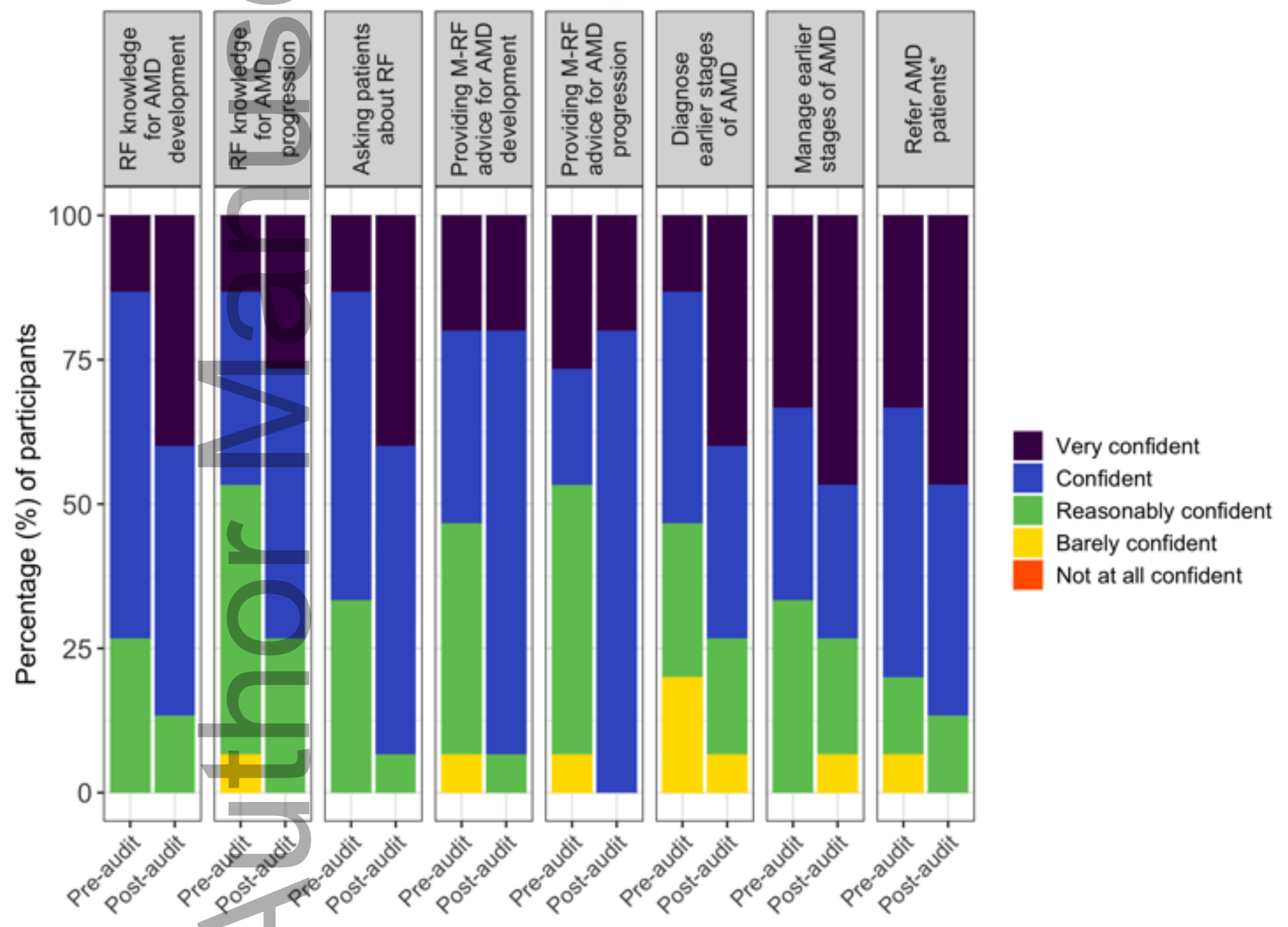

Figure 2. Self-reported confidence in AMD clinical care at the pre- and post-audit time points among participants $(n=15)$ who responded to both surveys. Participants indicated their level of confidence with each statement, using a five-step Likert scale comprising: not at all confident, barely confident, reasonably confident, confident and very confident.

$A M D$, age-related macular degeneration; $\mathrm{M}-\mathrm{RF}$, modifiable risk factors; $\mathrm{RF}$, risk factors 
* Refer AMD patients for medical retinal sub-specialist care

$\underline{\text { AMD clinical audit }}$

Each participant completed $15 \pm 7$ and $12 \pm 6$ (mean \pm SD) audits of unique patient records for the pre-and post-audit evaluation time points, respectively. Pre- and post-audit data for the level of compliance in individual audit domains are provided in supplementary materials (Appendices S1 and S2).

Patient demographics and risk factors. Comparing pre- and post-audit data, average compliance for clinical record keeping, per optometrist, showed improvements $(p<0.05)$ in the following domains: patient ethnicity (Figure 3A), driving status (Figure 3B), GP details (Figure 3C), family history of AMD (Figure 3E), current smoking status (Figure 3F), current dietary behaviours (Figure 3G), and current nutritional supplement intake (Figure 3H). Documentation of a patient's medical history did not change and had high compliance at both time points (Figure 3D).

Clinical examination. Figure 4 summarises the techniques that were documented to have been performed in patient consultations. Documentation of monocular BCVAs (Figure 4A) had high compliance, both pre- and post-audit. Compliance for documenting monocular pinhole VA (Figure 4B) and performing an in-office Amsler grid when indicated (Figure 4C) improved post-audit $(p<0.05)$. The average compliance for documenting any form of clinical posterior eye examination was high pre-audit and did not change (median: $100 \%$ at both time-points, $p=0.38$ ). Additional aspects that were unchanged post-audit were documentation of: performing a dilated retinal fundus examination (DFE, Figure 4D), and using any form of retinal imaging (Figure 4E). There was, however, an improvement in documenting use of OCT or referring for OCT imaging when indicated, post-audit (Figure $4 G)$. The average number of audits that documented performing retinal imaging without a DFE was lower post-audit (62\% to $48 \%, p=0.02$ ). 
Classification of AMD severity. The MaD-CCAT evaluated whether respondents classified AMD severity using the Beckman Classification, ${ }^{1}$ based on signs noted on the clinical record. Accurately recording disease severity improved for earlier stages of AMD (Figure 5, p < 0.05). There was a trend towards improved accuracy in documenting eyes with intermediate AMD (62\% versus $82 \%, p=0.15)$ and late AMD (68\% versus $80 \%, p=0.05)$, post-audit. Documenting the presence or absence of RPD improved post-audit (Figure 5A, $p<0.05$ ).

AMD management. The appropriateness of clinical management was assessed based on AMD severity in the more advanced eye (Figures 6 to 8). Documenting counselling about the benefits of smoking cessation (for current and/or prior smokers) and discussing the effect of smoking on AMD risk improved $(p<0.05)$ post-audit for patients with each of: normal maculae or normal ageing (Figure 6A), early AMD (Figure 7A) and intermediate AMD (Figure $8 A$ ). Evidence for discussing dietary and nutritional supplement behaviours also improved ( $p$ $<0.05$ ) post-audit for patients with normal maculae or normal ageing (Figure 6B), early AMD (Figure 7B) and intermediate AMD (Figure 8B).

For patients with early and intermediate AMD, recording whether the patient was advised of their risk of progression to late-stage disease did not change (Figures 7C and 8C, respectively). Provision of an Amsler grid and providing appropriate instructions for weekly home monitoring were analysed separately. For patients with early AMD, there was no change in documenting provision of an Amsler grid test (Figure 7D) or providing weekly home monitoring instructions (Figure 7E). For patients with intermediate AMD, there was an improvement $(p<0.05)$ in both Amsler grid provision (Figure $8 D$ ) and documenting weekly home monitoring instructions (Figure 8E). Nominating an appropriate review period for patients with each of normal maculae, normal ageing, early AMD and intermediate AMD were performed well at both the pre- and post-audit time points and did not change.

There were an insufficient number of audits for patients with different types of late-stage AMD to enable meaningful analyses: late AMD not requiring treatment (pre-audit median: 1.5, IQR: 2.8; post-audit median: 1.5, IQR: 2.0), definite/suspected recent onset CNV (preaudit 1.5, 2; post-audit $0.5,1$ ) and signs suggestive of CNV without symptoms (pre-audit 0, 0 ; pro-audit 0,0$)$. As a result, detailed data on late-stage AMD are not reported. 
A

Ethnicity

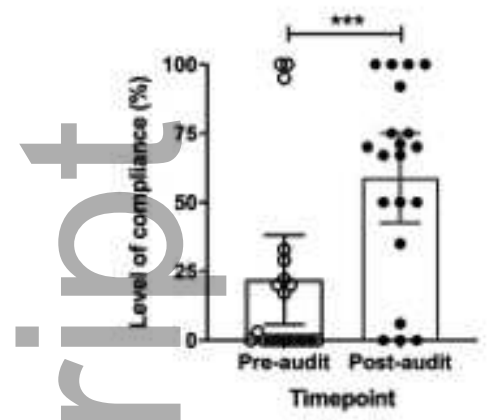

C General Practitioner details

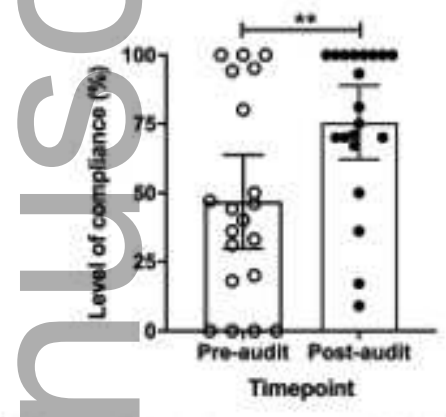

E Family history of $\mathrm{AMD}^{\dagger}$

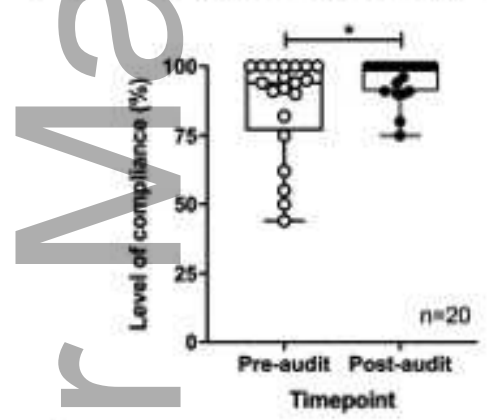

G Current dietary behaviours

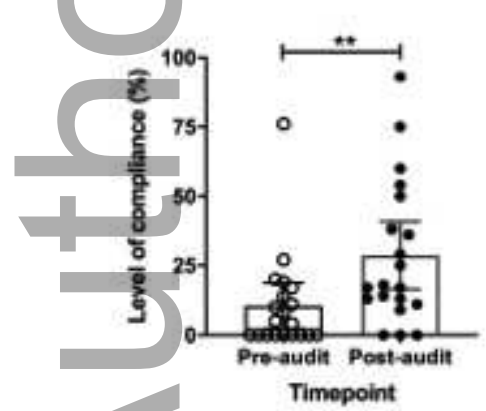

B

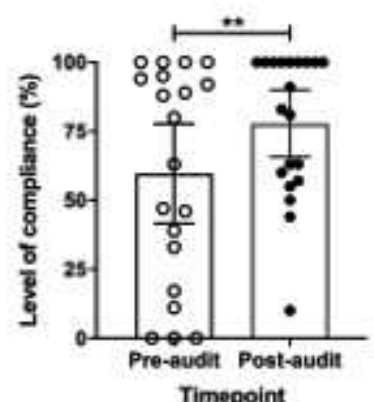

D

Medical history ${ }^{\dagger}$

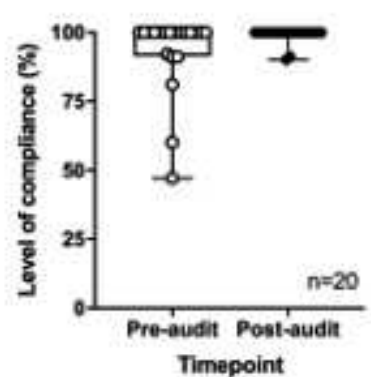

F Current smoking status

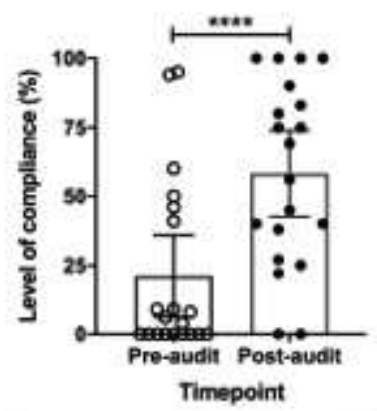

H Current nutritional supplement intake

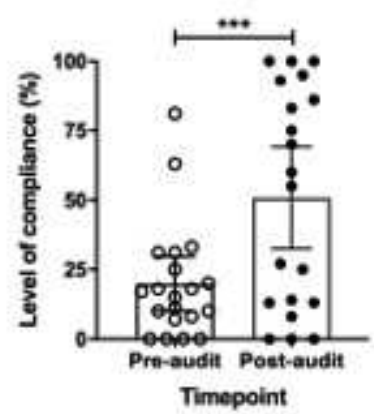

Figure 3. Clinical record documentation of patient demographics and AMD risk factors.

Plots show the level of compliance (\%) in each domain, both pre- and post-audit. Each data point represents the average level of compliance (\%), per participant, for patient: (A) Ethnicity; (B) Motor vehicle driving status; (C) General practitioner (GP) details; (D) General medical history; (E) Family history of AMD; (F) Current smoking status; (G) Current dietary 
behaviours relevant to $A M D$ and $(H)$ Current nutritional supplementation intake. Bars and error bars show mean and 95\% confidence intervals, respectively, for variables tested using paired t-tests. † Box and whisker plots show median and interquartile range, respectively, for non-parametric variables. ${ }^{*} p<0.05 ;{ }^{* *} p<0.01 ;{ }^{* * *} p<0.001 ;{ }^{* * * *} p<0.0001$.
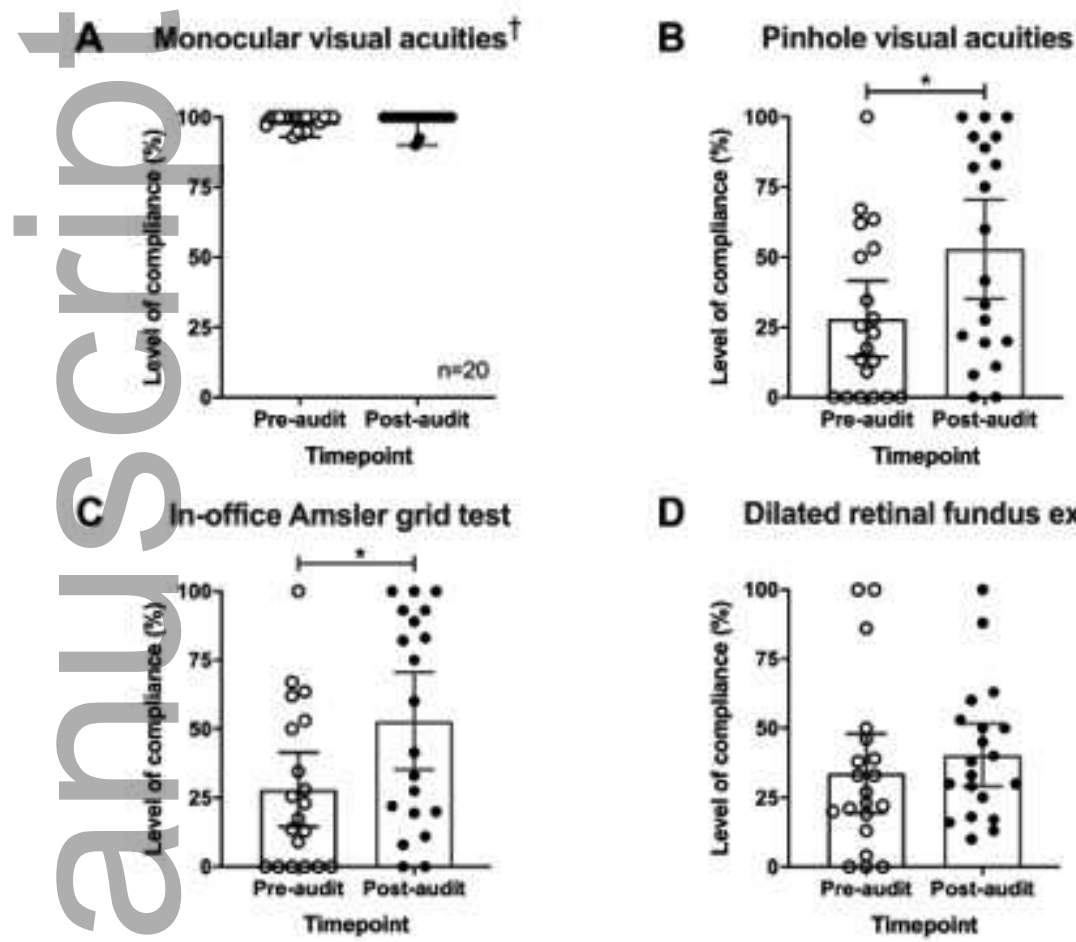

D Dilated retinal fundus examination
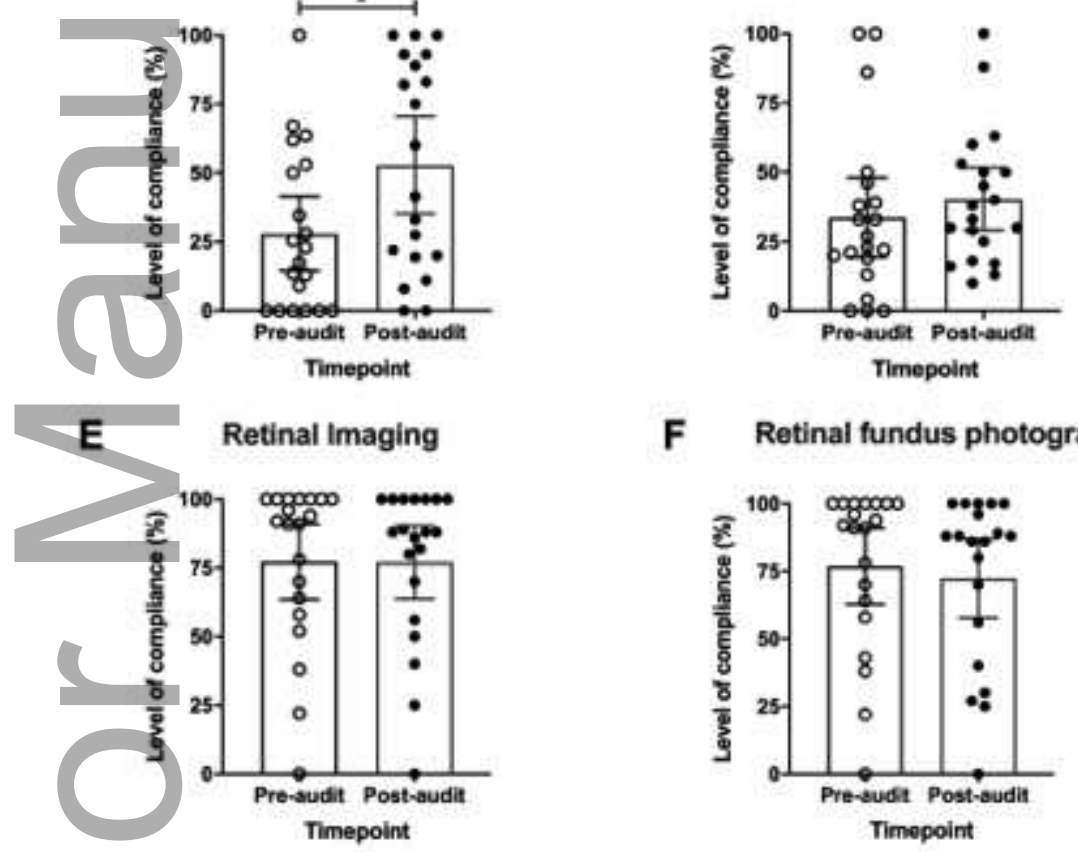

F Retinal fundus photography

G Optical Coherence Tomography
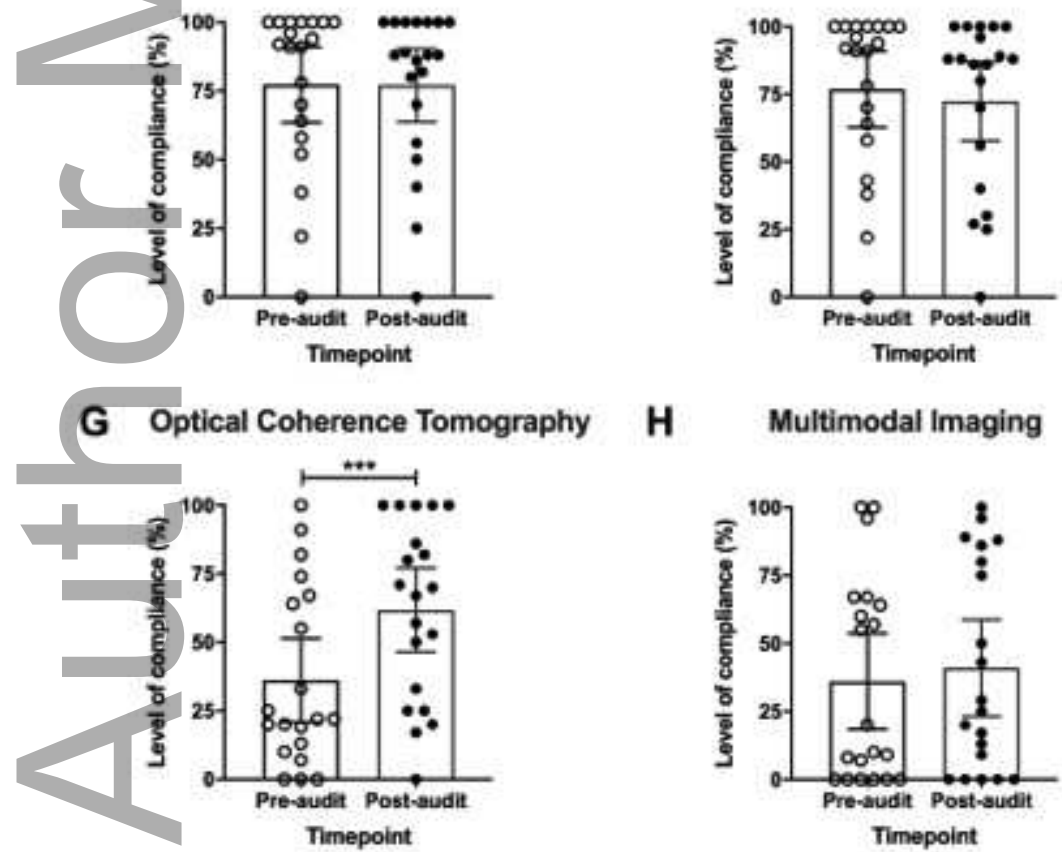

H Multimodal Imaging

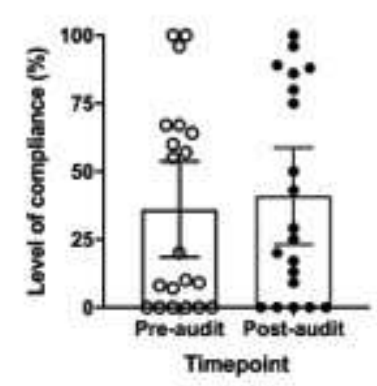

Figure 4. Clinical record documentation of clinical examination and imaging techniques.

Plots show the level of compliance (\%) in each domain, both pre-and post-audit. Each data point represents the average level of compliance (\%), per participant, for: (A) Monocular visual acuities (VA); (B) Pinhole VA (when indicated); (C) In-office Amsler grid testing (when This article is protected by copyright. All rights reserved 
indicated); (D) Dilated retinal fundus examination (DFE); (E) Any form of retinal imaging; (F) Retinal fundus photography; (G) Optical coherence tomography (OCT) (when indicated) and (H) Multimodal imaging such as fundus autofluorescence (FAF) and infrared (IR) imaging (when indicated). Bars and error bars show mean and $95 \%$ confidence intervals, respectively, for variables tested using paired t-tests. + Box and whisker plots show median and interquartile range, respectively, for nonparametric variables. ${ }^{*} p<0.05 ;{ }^{* *} p<0.01 ; * * *<<0.001$.

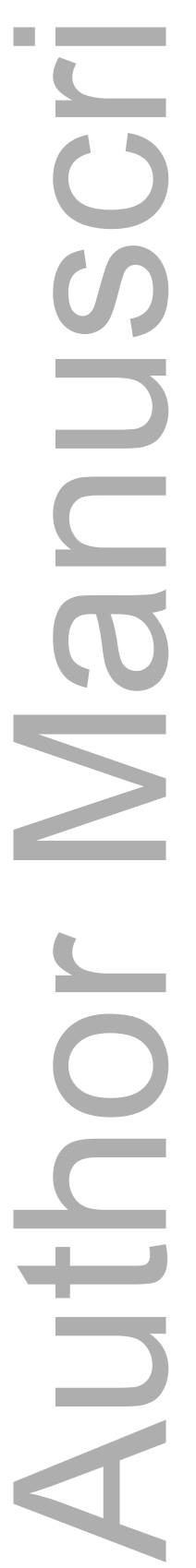


A Reticular pseudodrusen

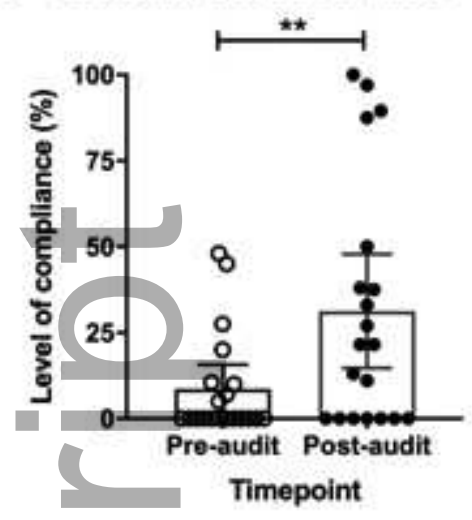

C Early AMD documented ${ }^{\dagger}$

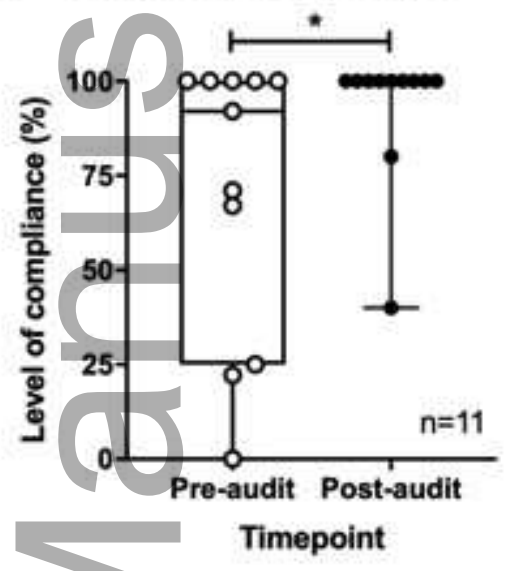

E Late AMD documented



B Normal macula/ageing documented ${ }^{\dagger}$

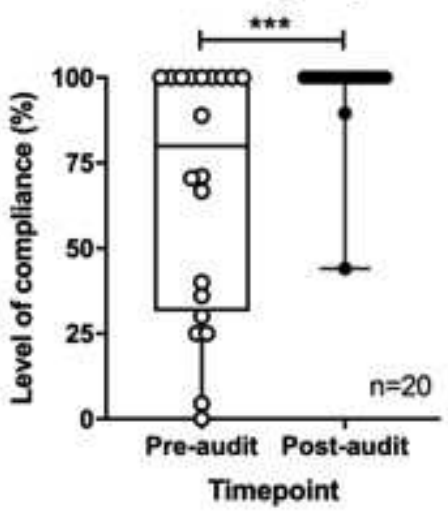

D Intermediate AMD documented

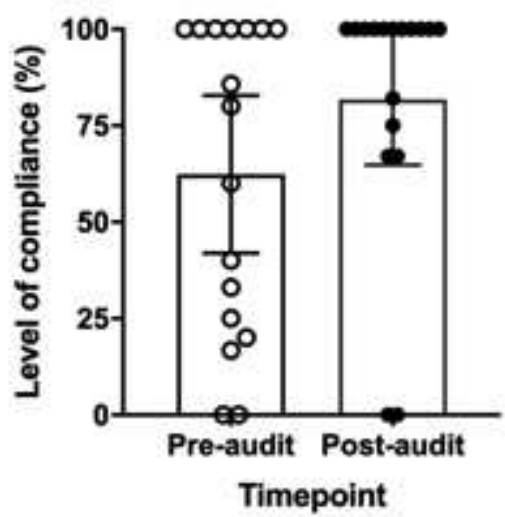

Figure 5. Clinical record documentation of reticular pseudodrusen and classification of AMD severity, per eye, according to the Beckman Classification (2013). ${ }^{1}$ Plots show the level of compliance (\%) in each domain, both pre- and post-audit. Each data point represents the average level of compliance (\%), per participant, for: (A) Reticular pseudodrusen; (B) Normal ageing changes; (C) Early AMD; (D) Intermediate AMD and 
(E) Late AMD documented. Bars and error bars show mean and 95\% confidence intervals, respectively, for variables tested using paired t-tests. + Box and whisker plots show median and interquartile range, respectively, for non-parametric variables. ${ }^{*} p<0.05 ;{ }^{* *} p<0.01 ;{ }^{* * *} p<0.001$.

\section{Normal maculae/Normal Ageing Changes Management}
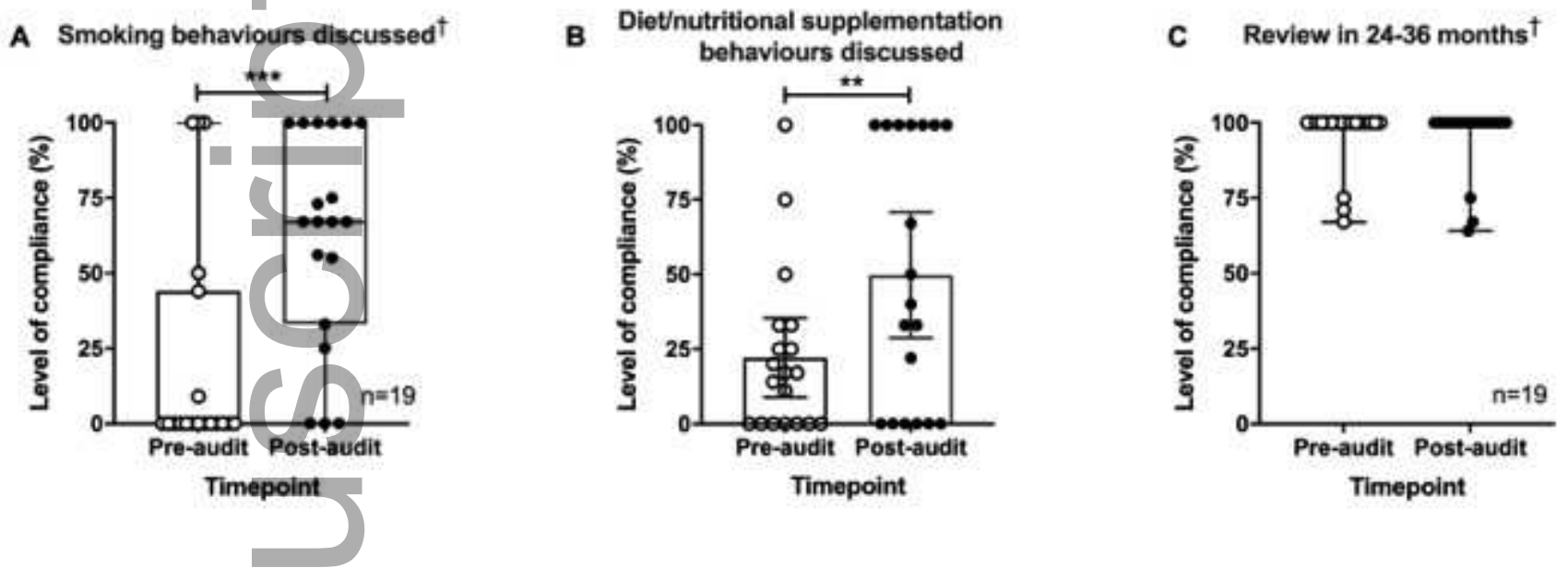

Figure 6. Clinical record documentation of management for patients with normal maculae or normal ageing changes. Plots show the level of compliance (\%) in each domain, both preand post-audit. Each data point represents the average level of compliance (\%), per participant, for: (A) Counselling about smoking behaviours to reduce AMD development and progression; (B) Recommended dietary behaviours and appropriate nutritional supplementation relevant to AMD and (C) Appropriate review period of 24-36 months according to the 2018 RANZCO AMD referral pathway. ${ }^{36}$ Bars and error bars show mean and $95 \%$ confidence intervals, respectively, for variables tested using paired t-tests. + Box and whisker plots show median and interquartile range, respectively, for non-parametric variables. ${ }^{* *} p<0.01 ; * * * 0<0.001$.

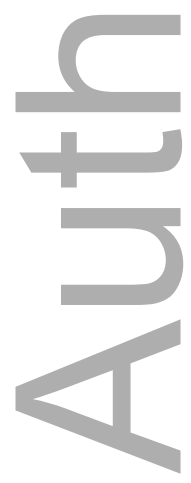




\section{Early AMD Management}

A Smoking behaviours discussed

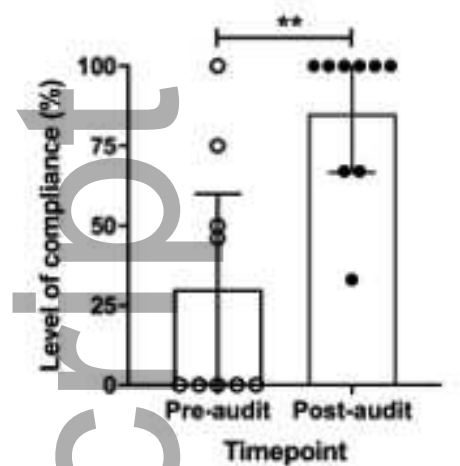

C Risk of AMD progression discussed ${ }^{\dagger}$

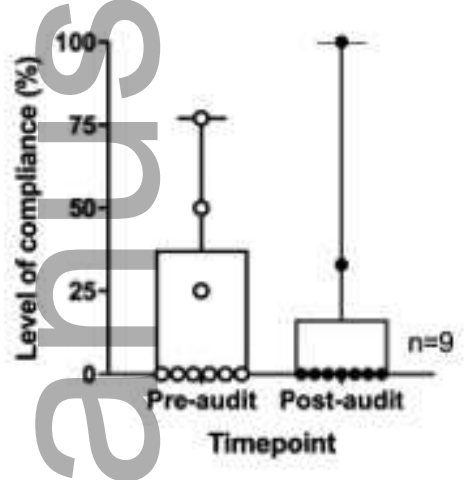

E
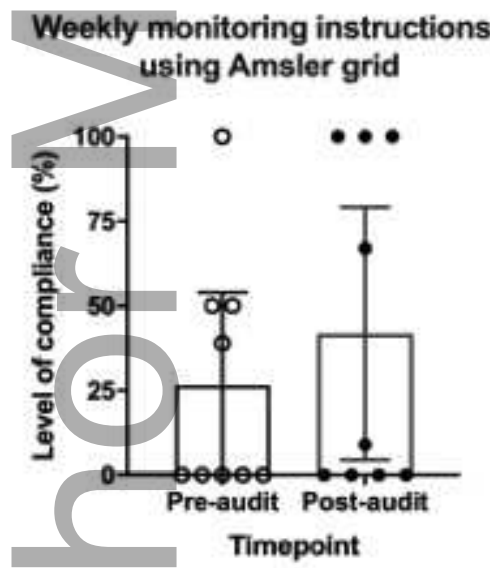

B
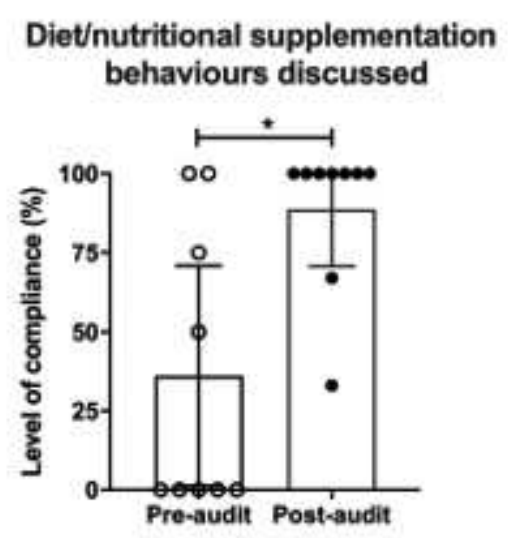

Timepoint

D Amsler grid provision for home monitoring

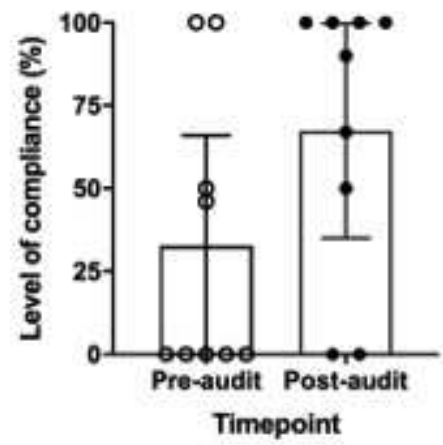

$\mathbf{F}$

Review in 12 months ${ }^{\dagger}$



Figure 7. Clinical record documentation of management for patients with early AMD.

Plots show the level of compliance (\%) in each domain, both pre- and post-audit. Each data point represents the average level of compliance (\%), per participant, for: (A) Counselling about smoking behaviours to reduce AMD progression; (B) Recommended dietary behaviours and appropriate nutritional supplementation relevant to AMD; (C) Risk of AMD progression, based on clinical signs and risk factors; (D) Provision of Amsler grid for home use; (E) Providing instructions for weekly home self-monitoring using the Amsler grid and (F) Appropriate review period of 12 months according to the 2018 RANZCO AMD referral pathway. ${ }^{36}$ Bars and error bars show mean and 95\% confidence intervals, respectively, for variables tested This article is protected by copyright. All rights reserved 


\section{Intermediate AMD management}

A Smoking behaviours discussed ${ }^{\dagger}$

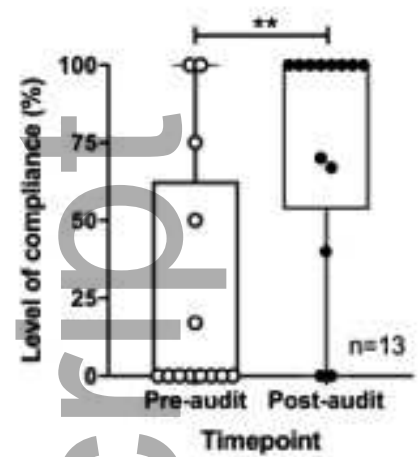

C Risk of AMD progression discussed

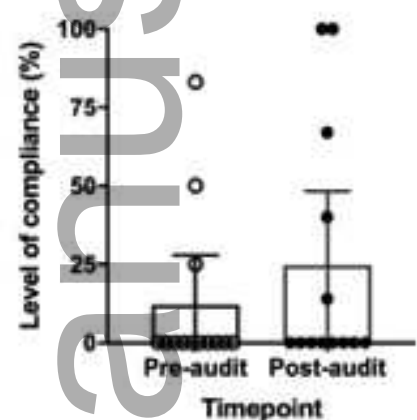

E

\section{Weekly monitoring instructions}

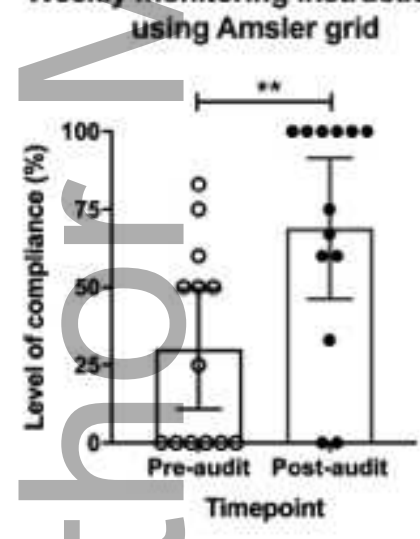

B

$$
\text { Diet/nutritional supplementation }
$$
behaviours discussed

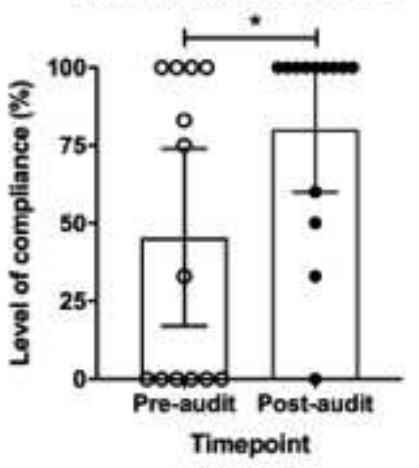

D Amsler grid provision for home monitoring

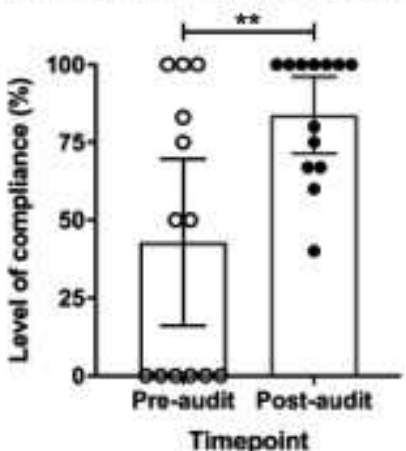

$\mathbf{F}$ Review in 6-12 months ${ }^{\dagger}$

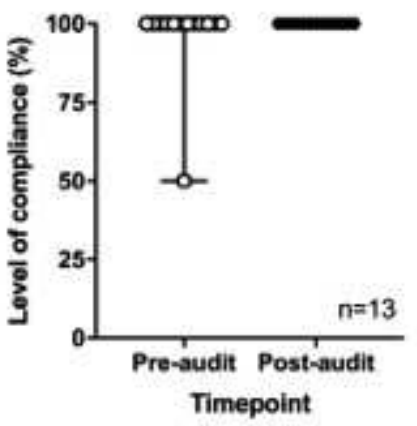

using paired t-tests. + Box and whisker plots show median and interquartile range, respectively, for nonparametric variables. ${ }^{*} p<0.05 ;{ }^{* *} p<0.01$. Figure 8 . Clinical record documentation of management for patients with intermediate AMD. Plots show the level of compliance (\%) in each domain, both pre- and post-audit. Each data point represents the average level of compliance (\%), per participant, for:

(A) Counselling about smoking behaviours to reduce AMD progression;

(B) Recommended dietary behaviours and appropriate nutritional supplementation relevant to AMD; (C) Risk of AMD progression based on clinical signs and risk factors; (D) Provision of 
Amsler grid for home use; (E) Providing accurate instructions for weekly home selfmonitoring using the Amsler grid; (F) Appropriate review period of 6-12 months according to the 2018 RANZCO AMD referral pathway guidelines. ${ }^{36}$ Bars and error bars show mean and 95\% confidence intervals, respectively, for variables tested using paired t-tests. + Box and whisker plots show median and interquartile range, respectively, for non-parametric variables. ${ }^{*} p<0.05,{ }^{* *} p<0.01$.

Self-nominated clinical areas for improvement based on pre-audit analytical data: Based on self-evaluating the pre-audit analytical data, the most common areas nominated by participants for self-improvement were: documenting smoking status (90\%), capturing current dietary behaviours (60\%), performing an Amsler grid test in-office when indicated (55\%), documenting the presence or absence of RPD (45\%) and discussing the risk of progression to late-stage AMD (45\%). Thirteen participants requested additional resources to support practice improvement in their nominated area(s), seven participants were emailed relevant peer-reviewed research papers and six were directed to resources in the appendices in the MaD-CCAT supporting manual (including unpublished tools for quantitative patient smoking and dietary behaviours, developed by LED and PRK).

Considering the pre- versus post-audit compliance for participants that self-nominated each area for improvement, Figure 9 shows improvements $(p<0.05)$ in recording a patient's current smoking status (Figure 9A), performing Amsler grid in-office when indicated (Figure 9C) and documenting RPD assessment (Figure 9D). For documenting current dietary behaviours, there was no significant change to the level of compliance post-audit (Figure $9 \mathrm{~B})$. There were insufficient data to assess changes in compliance for discussing risk of progression to late-stage AMD.

\section{Clinical audit experience post-study survey}

Of the 20 participants who were emailed the post-study survey, 13 completed the section reporting their level of agreement to statements relating to the utility of the MaD-CCAT and clinical audit (Figure 10). Most participants agreed that the MaD-CCAT provided valuable insight into documentation of the care provided to people with AMD (93\%), allowed them to self-identify areas for improvement (92\%), and the analytical data were easy to interpret and consistent with their expectations (70\%). Most respondents (92\%) did not agree that the MaD-CCAT was time efficient and nearly half of respondents considered the continuing professional development (CPD) to be a major incentive for participation.

This article is protected by copyright. All rights reserved 


\section{Area for improvement}

A Current smoking status

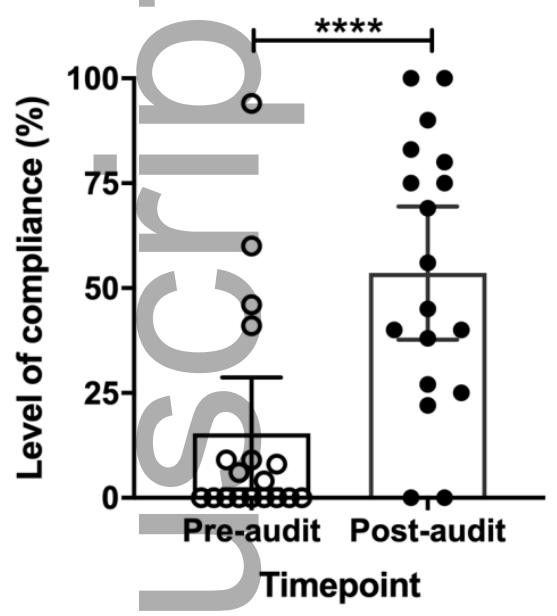

C In-office Amsler grid test

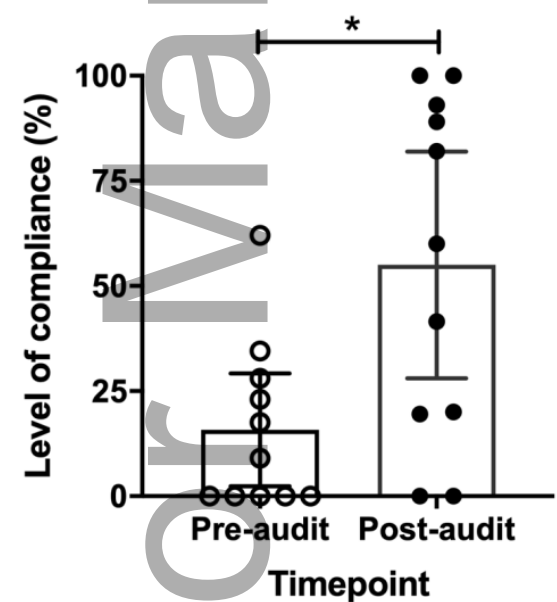

B Current dietary behaviours

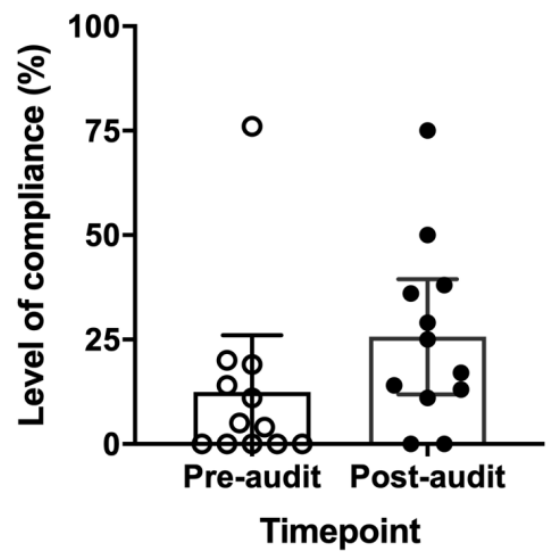

D

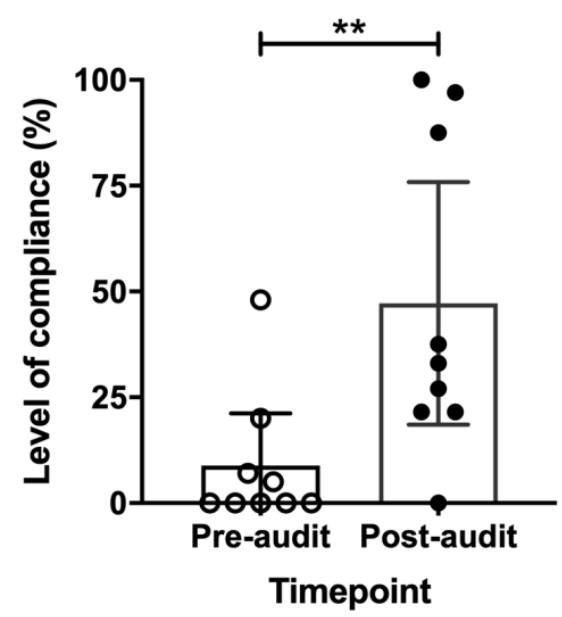

Figure 9. Changes in clinical record documentation for commonly self-identified areas for improvement. Plots show the level of compliance (\%) in each domain, both pre- and postaudit. Each data point represents the average level of compliance (\%), per participant, for documenting: (A) Current smoking status; (B) Current dietary behaviours relevant to AMD; (C) In-office Amsler grid testing (when indicated) and (D) Reticular pseudodrusen (RPD) assessment. Bars and error bars show mean and $95 \%$ confidence intervals, respectively. ${ }^{*} p<0.05 ;{ }^{* *} p<0.01$; $* * * * p<0.0001$. 


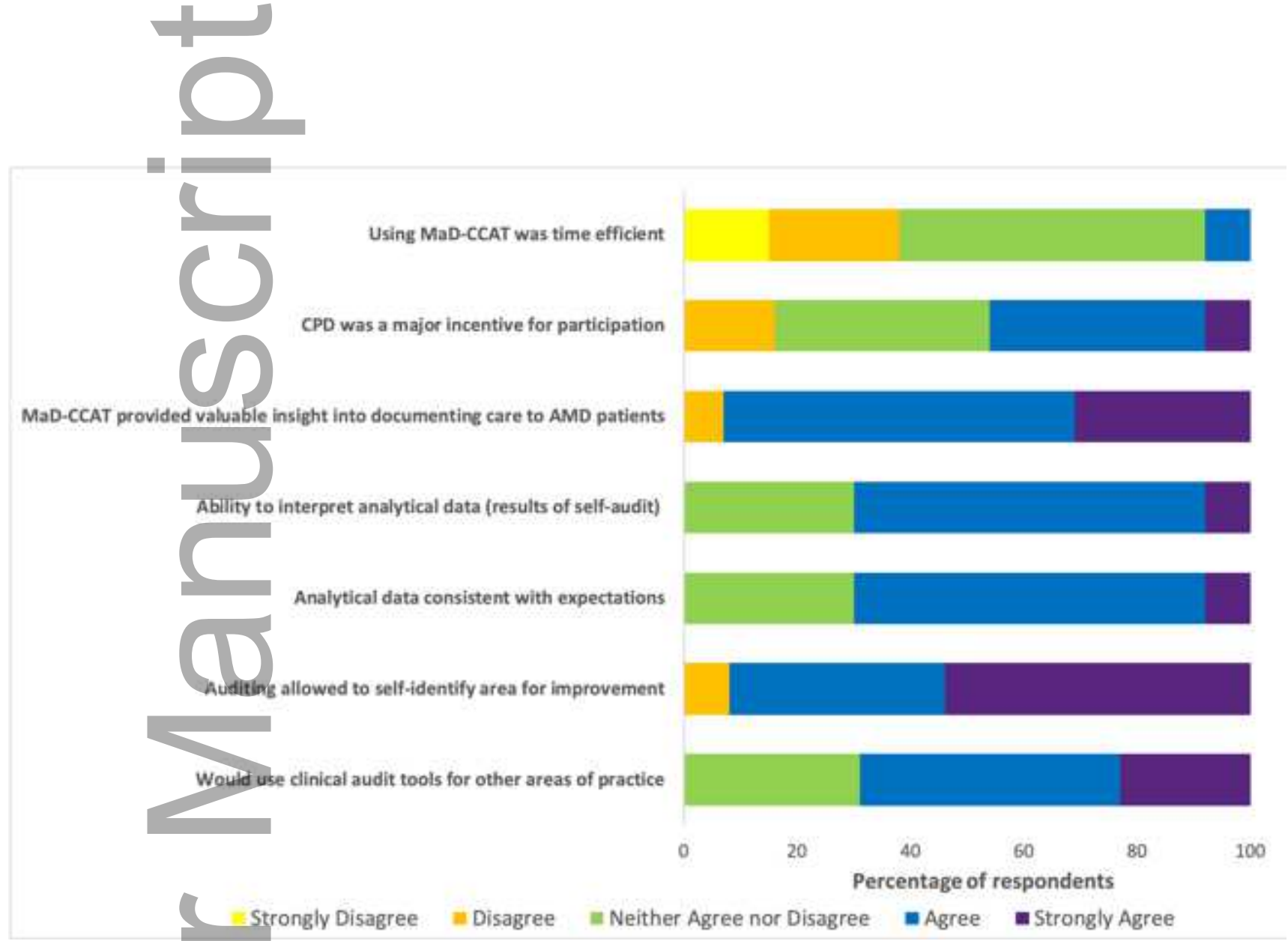

Figure 10. Stacked bar chart showing participants $(n=13)$, who indicated their level of agreement, with each statement for various aspects of the MaD-CCAT and clinical audit, at the end of the study, using the following five-step Likert scale: strongly disagree, disagree, neither agree nor disagree, agree and strongly agree.

AMD, Age-related Macular Degeneration; CPD, Continuing Professional Development; MaD-CCAT, Macular Degeneration Clinical Care Audit Tool

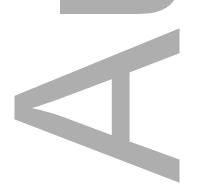

\section{Discussion}

This article is protected by copyright. All rights reserved 
This study analysed self-reported audit data from optometric clinical records, to gain insight into the eye care provided to people with, or at risk of, AMD. By comparing data at two time points, this study investigated whether auditing and receiving analytical feedback was useful for enhancing the documentation of optometric care, as a proxy to measure the clinical care provided to those with AMD. Whilst not necessarily reflecting all aspects of care delivery, clinical audit of records is considered an appropriate means for assessing the quality of care. ${ }^{31}$ We found that self-audit with feedback improved documentation for several aspects of care, including AMD risk factors, monocular pinhole VA, Amsler grid test results and accurate classification of AMD severity. Post-audit, optometrists identified performing OCT imaging more frequently, and more consistently documented lifestyle modification advice for patients with earlier stages of AMD. Most participants (92\%) agreed that the MaD-CCAT audit tool allowed them to readily self-identify practice areas for practice improvement.

\section{Efficacy of clinical audit}

In the field of medicine, audit has been shown to improve clinical record documentation $\mathrm{n}^{31,43,44}$ and patient care. ${ }^{45-49}$ However, to our knowledge few studies have assessed the value of clinical audit in eye care..$^{37-39}$ In the present study, self-audit with feedback improved the subsequent documentation of key aspects of AMD care in patient clinical records. Studies in various disciplines have investigated audit and feedback as an intervention for optimising patient care. McKay-Brown et al. found that GPs who participated in clinical audit with an associated education session altered their approach to managing patient smoking cessation. ${ }^{50}$ Other studies of clinical audit and feedback have shown improvements in achieving timely breast cancer management, ${ }^{48}$ completeness of electronic medical records in a hospital emergency department, ${ }^{31,51}$ documentation of clinical processes necessary for optimal diabetes management ${ }^{43}$ and comprehensive assessment and documentation of clinical histories in an Australian health centre. ${ }^{52}$

At baseline, many participants in the present study felt confident in their knowledge of AMD risk factors (55\%) and asking patients about such factors (60\%). However, the pre-audit data indicated considerable scope for improvement in these domains, with most respondents not having documented patient smoking status (79\%), dietary behaviours (89\%), nutritional supplementation (80\%) or ethnicity (78\%). Similarly, although half of participants felt 
confident in managing AMD by providing counselling about modifiable risk factors, their quantified level of compliance for counselling about smoking and diet/nutritional supplementation was $25 \%$ and $34 \%$ of initial audits, respectively. Self-audit using the MaDCCAT likely served as a reminder of the importance of these management practices, as supported by the observed improvement in these domains post-audit. Previous survey data suggested that some optometrists consider smoking counselling to be a medical issue that is primarily the responsibility of the patient's GP. ${ }^{29}$ However, smoking has been linked to other ocular conditions, ${ }^{53,54}$ supporting the importance of optometrists documenting their patient's smoking status. Furthermore, many patients (70\%) indicate feeling comfortable discussing their smoking habits with their optometrist. ${ }^{6}$

Clinical audit is important for both identifying good practice and opportunities for training and further education. ${ }^{33}$ We observed a significant post-audit improvement in accurately documenting AMD severity using the Beckman Initiative for Macular Disease Classification, ${ }^{1}$ for patients with normal maculae, normal ageing, early AMD and late AMD. Documenting provision of an Amsler grid test and instructing patients regarding its use improved for intermediate AMD (43\% to $84 \%$ ) post-audit; however it did not alter for patients with early AMD. This finding suggests that participants' post-audit clinical efforts may have been focussed on implementing changes to care for patients at the greatest risk of late-stage AMD, based upon their disease phenotype. The MaD-CCAT aimed to improve participants' knowledge of AMD severity staging by providing the correct classification after entering a patient's documented clinical signs, thus serving as an educative tool. Similar improvements have been reported in studies that have assessed the effect of audit and/or educational interventions on clinical record keeping in other disciplines. ${ }^{49-51,55-57}$ Consistent with these findings, Bowie et al. (2012) suggested placing education at the centre of clinical audit enhanced the effectiveness of the process. ${ }^{58}$

\section{Importance of analytical data for providing feedback}

Participants showed improvements in documenting monocular pinhole VA and in-office Amsler grid tests, post-audit. These tests assist in raising suspicion about the presence of CNV and thus can support timely referral for a confirmed diagnosis and anti-VEGF intervention, to optimise patient outcomes. ${ }^{59,60}$ There was a similar improvement in 
documenting use of OCT imaging (from $36 \%$ pre-audit to $62 \%$ post-audit), and documenting RPD assessment (from 9\% pre-audit to $31 \%$ post-audit). RPD is a relatively new clinical sign that is linked to an increased risk of progression to late AMD. ${ }^{61-63}$ RPD is not incorporated into current AMD classification systems and has poor visibility on clinical examination and retinal fundus photography. ${ }^{64,65}$ Therefore, RPD may not be widely recognised by clinicians. We propose that the improved result post-audit may be due to the analytical feedback provided to participants following pre-audit in increasing awareness of RPD and the importance of performing OCT. Puvanachandra et al. auditing glaucoma services in a hospital setting also found that providing participants with analytical data, clear targets and methods for improving results of the initial audit significantly improved post-audit outcomes. ${ }^{39}$ Most participants (70\%) in our study agreed that the analytical data was easy to interpret and consistent with their expectations. Consistent with findings in a systematic review by Ivers et al., providing feedback about performance, relative to best practice standards, allows clinicians to self-reflect on their performance. ${ }^{32}$

\section{Practices areas unchanged by clinical audit}

Documentation of performing a DFE was an area that did not change post-audit but had potential for improvement at baseline (compliance (\%): pre-audit 34\% versus post-audit 40\%). This may be, at least in part, due to the widespread availability of retinal imaging, ${ }^{66}$ which could be viewed as a time efficient method for permanently documenting retinal signs. ${ }^{66,67}$ That said, our results indicate that post-audit fewer practitioners used retinal imaging without performing a DFE. The need for routine DFE is well established in diabetes due to high rates of missed diabetic retinopathy. ${ }^{3}$ DFE is also recommended for AMD assessment to allow for a thorough assessment of the macula. Mydriatic ocular examination, particularly with combined retinal imaging, reduces artefacts for eyes with lenticular opacities that may otherwise obstruct the retinal view. ${ }^{68-70}$ Several studies assessing the reason for clinicians not performing relevant clinical tests was due to perceived insufficient clinical time. ${ }^{44,71,72}$ Another potential contributory factor for the observed lack of change in DFE documentation may be the adopted method for providing feedback. Participants in our study self-audited their practice, which is considered to "promote a sense of responsibility" and "empower them to take action in improving the quality of care". ${ }^{43}$ However, providing clinicians with feedback multiple times, and in various 
formats, is preferable for modifying practice behaviours. ${ }^{32} \mathrm{~A}$ more interactive feedback process, involving discussion with participants after the pre-audit about areas for improvement, and the institution of well-structured action plans may have elicited an enhanced behavioural change. ${ }^{33}$ However, the drawback of this time-intensive process is that it is unlikely to reflect the real-world scenario of optometry practice, which is dominated by clinicians practising in settings who would be reliant on self-audit.

A general consideration relating to the interpretation of clinical audit data is the potential that clinicians may not fully record patient discussions and management advice on their records. Mismatches can occur between what occurs in a consultation and what is documented on the clinical record. Discrepancies between clinical record notes and patientreported symptoms were investigated by Valikodath et al., who found that many patients recorded more symptoms on an eye symptom questionnaire compared to symptoms recorded on electronic medical records. ${ }^{73}$ The authors suggested the discrepancy could reflect differences in terminology, clinicians not fully recording reported symptoms or a tendency to focus on more troublesome symptoms. ${ }^{73} \mathrm{~A}$ study that analysed pain care delivered to patients found that half of patients recalled receiving management advice, although only $14 \%$ of these patients' clinical records had the advice documented; 74 this finding suggests that clinical records may underestimate aspects of patient care delivery. Garcia et al. also found more patients reported receiving smoking cessation advice relative to the number of clinical records documenting this advice. ${ }^{75}$

In considering limitations of this study, the participants self-audited their own patient records, without independent re-audit. This may have also led to potential biases and an over-stating of their clinical care, including a contributory role of the Hawthorne effect. This term was introduced in 1953 and is used to describe the potential improvement in clinical performance due to the clinician's awareness of being studied or audited. ${ }^{48,76,77}$ Several studies attribute changes in clinical performance as a result of clinical audit to the Hawthorne effect. For example, Esposito et al. reported the announcement of an audit of hypertension management and found this to cause a decreased prevalence of hypertension in patients on haemodialysis after a period of time. ${ }^{45}$ 
Self-audit may have also led to potential bias in the entered data, based on clinician's knowledge of AMD and not necessarily what was documented on the patient's clinical record. Although participants were specifically instructed to enter only what was documented on each patient record, it is possible that (contrary to these directions) some participants may have responded based on recalled discussions or interactions with specific patients. Govender et al. contend that clinical auditing using patient notes is the preferred method for assessing care provision, as opposed to directly observing practices as this may influence clinician behaviour for the observed clinical examinations. ${ }^{43}$ Future studies could randomly check self-audit data entries to examine the rigour of the approach adopted in the present study.

In this study, the pre- and post-audit evaluation periods were three months each. Future studies may consider enrolling more participants and providing performance feedback, and re-auditing clinical records over a longer time period or regular intervals to assess whether improvements are sustained. Including more participants may also better represent the overall practice patterns of Australian optometrists. Our study was also somewhat limited by the number of audits of patients with late-AMD conducted per participant, and therefore a comparison of the clinical management of such patients was not possible. A longer audit period may allow for more patients with late-stage AMD to be identified.

\section{Barriers to clinical audit}

Although a convenience sample of 50 participants initially enrolled in this study, 30 withdrew or were lost to follow-up. The most frequently reported reason was concern about the time commitment. Most participants (92\%) in our study did not agree that selfaudit using the MaD-CCAT was time efficient, which is a substantial barrier to clinicians incorporating audit into their practice. Several studies have found that clinicians consider time spent auditing as time better used to provide clinical care. ${ }^{45,46,58,78,79}$ Bowie and colleagues identified "work pressure" and "lack of protected time" as major barriers to clinical audit among healthcare workers. ${ }^{58}$ These authors also reported that clinicians may be doubtful about conducting a clinical audit if the process was considered more work, imposed, or unnecessary because current services were already performed well. Auditing may also be difficult for clinicians working across multiple practice locations, due to limited 
access to patient records. Nearly all participants $(93 \%)$ in our study agreed that self-audit with analytical feedback provided valuable insight into their care provision and improved their AMD knowledge. Taken together, these findings suggest that time-efficient methods for implementing optometric clinical audit would likely be acceptable to the profession.

Clinical records are crucial for capturing and reflecting the clinical care provided to patients, facilitating communication between clinicians, and reducing possible medico-legal risk. Our data demonstrate that self-audit with analytical feedback improves the self-evaluated clinical record documentation by optometrists of AMD risk factors, clinical examination techniques, classification of AMD severity and management advice provided to people with, or at risk of, AMD. These findings support a role for audit for improving clinical record keeping by optometrists and may be indicative of improvements in practice. As in other healthcare disciplines, this study also identifies a need for effective audit to be time efficient, so as to improve clinician engagement with this important activity, aimed at improving patient care.

\section{Acknowledgements}

This study was funded by a 2015 Blackmores Research Grant from the Macular Disease Foundation Australia (awarded to LED, PRK, LNA and RHG), a 2015 National Health and Medical Research Council (NHMRC) of Australia Translating Research Into Practice (TRIP) Fellowship (awarded to LED, APP1091833), a 2019 NHMRC Medical Research Future Fund Next Generation Clinical Researcher Fellowship (awarded to LNA, APP1151055) and a 2016 NHMRC Fellowship (awarded to RHG, GNT1103013).

Disclosures

RHG sits on advisory boards for Novartis, Bayer, Roche/Genentech, Apellis, for work unrelated to that presented here. LED has current funding from CooperVision and Azura Ophthalmics, for research in the field of dry eye disease, and sits on an advisory board for Seqirus for work unrelated to that presented here.

\section{References}

1. Ferris FL, $3^{\text {rd }}$, Wilkinson $\mathrm{CP}$, Bird A et al. Clinical classification of age-related macular degeneration. Ophthalmology 2013;120:844-851. 
2. Wong WL, Su X, Li X et al. Global prevalence of age-related macular degeneration and disease burden projection for 2020 and 2040: a systematic review and metaanalysis. Lancet Glob Health 2014;2:e106-e116.

3. Liu L, \& Swanson, M. Improving patient outcomes: role of the primary care optometrist in the early diagnosis and management of age-related macular degeneration. Clin Optom 2013; 2013:1-12.

4. Yonekawa Y, Miller JW \& Kim IK. Age-Related Macular Degeneration: Advances in Management and Diagnosis. J Clin Med 2015;4:343-359.

5. Nebbioso M, Lambiase A, Cerini A, et al. Therapeutic Approaches with Intravitreal Injections in Geographic Atrophy Secondary to Age-Related Macular Degeneration: Current Drugs and Potential Molecules. Int J Mol Sci 2019;20:1693.

6. Downie LE, Douglass A, Guest D \& Keller PR. What do patients think about the role of optometrists in providing advice about smoking and nutrition? Ophthalmic Physiol Opt 2017;37:202-211.

7. Downie LE \& Keller PR. Nutrition and age-related macular degeneration: Research evidence in practice. Optom Vis Sci 2014;91:821-831.

8. Lambert NG, ElShelmani H, Singh MK, et al. Risk factors and biomarkers of agerelated macular degeneration. Prog Retin Eye Res 2016;54:64-102.

9. Chakravarthy $\mathrm{U}$, Wong $\mathrm{T}$, Fletcher $\mathrm{A}$, et al. Clinical risk factors for age-related macular degeneration: a systematic review and meta-analysis. BMC Ophthalmol 2010;10:31.

10. Mitchell P, Liew G, Gopinath B \& Wong TY. Age-related macular degeneration. Lancet 2018;392:1147-1159.

11. Cook HL, Patel PJ \& Tufail A. Age-related macular degeneration: diagnosis and management. Br Med Bull 2008;85:127-149.

12. Shahid H, Khan JC, Cipriani V, et al. Age-related macular degeneration: the importance of family history as a risk factor. Br J Ophthalmol 2012;96:427-431.

13. Al-Zamil WM \& Yassin SA. Recent developments in age-related macular degeneration: a review. Clin Interv Aging 2017;12:1313-1330.

14. Srinivasan S, Swaminathan G, Kulothungan V, Sharma T \& Raman R. The association of smokeless tobacco use and pack-years of smokeless tobacco with age-related macular degeneration in Indian population. Cutan Ocul Toxicol 2017;36:253-258. 
15. Khan JC, Thurlby DA, Shahid $\mathrm{H}$, et al. Smoking and age related macular degeneration: the number of pack years of cigarette smoking is a major determinant of risk for both geographic atrophy and choroidal neovascularisation. Br J Ophthalmol 2006;90:75-80.

16. Thornton J, Edwards R, Mitchell P, Harrison RA, Buchan I \& Kelly SP. Smoking and age-related macular degeneration: a review of association. Eye (Lond) 2005;19:935944.

17. Neuner B, Komm A, Wellmann J, et al. Smoking history and the incidence of agerelated macular degeneration--results from the Muenster Aging and Retina Study (MARS) cohort and systematic review and meta-analysis of observational longitudinal studies. Addict Behav 2009;34:938-947.

18. Bott $D$, Huntjens B \& Binns A. Nutritional and smoking advice recalled by patients attending a UK age-related macular degeneration clinic. J Public Health (Oxf) 2018;40:614-622.

19. Evans JR, Fletcher AE \& Wormald RP. 28,000 Cases of age related macular degeneration causing visual loss in people aged 75 years and above in the United Kingdom may be attributable to smoking. Br J Ophthalmol 2005;89:550-553.

20. Kaushik S, Wang JJ, Flood V, et al. Dietary glycemic index and the risk of age-related macular degeneration. Am J Clin Nutr 2008;88:1104-1110.

21. Christen WG, Schaumberg DA, Glynn RJ \& Buring JE. Dietary omega-3 fatty acid and fish intake and incident age-related macular degeneration in women. Arch Ophthalmol 2011;129:921-929.

22. Gopinath B, Flood VM, Louie JC, et al. Consumption of dairy products and the 15year incidence of age-related macular degeneration. Br J Nutr 2014;111:1673-1679.

23. Chong EW-T, Simpson JA, Robman LD et al. Red Meat and Chicken Consumption and Its Association With Age-related Macular Degeneration. Am J Epidemiol 2009;169:867-876.

24. Chapman NA, Jacobs RJ \& Braakhuis AJ. Role of diet and food intake in age-related macular degeneration: a systematic review. Clin Exp Ophthalmol 2019;47:106-127.

25. de Koning-Backus APM, Buitendijk GHS, Kiefte-de Jong JC et al. Intake of Vegetables, Fruit, and Fish is Beneficial for Age-Related Macular Degeneration. Am J Ophthalmol 2019;198:70-79. 
26. Hogg RE, Woodside JV, McGrath A, et al. Mediterranean Diet Score and Its Association with Age-Related Macular Degeneration: The European Eye Study. Ophthalmology 2017;124:82-89.

27. Age-Related Eye Disease Study 2 Research Group. Lutein + zeaxanthin and omega-3 fatty acids for age-related macular degeneration: the Age-Related Eye Disease Study 2 (AREDS2) randomized clinical trial. JAMA 2013;309:2005-2015.

28. Age-Related Eye Disease Study Research Group. A randomized, placebo-controlled, clinical trial of high-dose supplementation with vitamins $\mathrm{C}$ and $\mathrm{E}$, beta carotene, and zinc for age-related macular degeneration and vision loss: AREDS report no. 8. Arch Ophthalmol 2001;119:1417-1436.

29. Downie LE \& Keller PR. The self-reported clinical practice behaviors of Australian optometrists as related to smoking, diet and nutritional supplementation. PloS One 2015;10:e0124533.

30. Pullen I \& Loudon J. Improving standards in clinical record-keeping. Adv Psychiatr Treat 2018;12:280-286.

31. Mohammadi-Sardo MR, Salehi S, Sotoodehnia M \& Rasooli F. The effectiveness of continuous quality improvement system establishment on improvement of the data recording quality in the emergency department: A clinical audit. Acta Medica Iranica 2018;56:598-603.

32. Ivers N, Jamtvedt G, Flottorp S, et al. Audit and feedback: effects on professional practice and healthcare outcomes. Cochrane Database Syst Rev 2012:CD000259.

33. Bennadi D, Konekeri V, Kshetrimayum N, Sibyl S \& Reddy V. Clinical Audit-A Literature Review. J Int Dent Med Res 2014;7:49-55.

34. Borbasi S, Jackson D \& Lockwood C. Undertaking a clinical audit. Using evidence to guide nursing practice (Courtney M \& McCutcheon $\mathrm{H}$, editors), $2^{\text {nd }}$ edition, Elsevier: Australia, 2010; pp.113-132.

35. Graham WJ. Criterion-based clinical audit in obstetrics: bridging the quality gap? Best Pract Res Clin Obstet Gynaecol 2009;23:375-388.

36. Ophthalmologists RANZCO. RANZCO Referral Pathway for AMD Screening. Surry Hills, NSW: RANZCO 2018, https://ranzco.edu/wpcontent/uploads/2020/01/080120-RANZCO-Referral-pathway-for-AMDmanagement-revised.pdf, accessed 1/7/20. 
37. Ho KC, Stapleton F, Wiles L, Hibbert P, White A \& Jalbert I. iCareTrack: measuring the appropriateness of eyecare delivery in Australia. Ophthalmic Physiol Opt 2020; 40:433-441.

38. Lindsay J, Bickerstaff D, McGlade A, Toner A \& Jackson AJ. Low vision service delivery: an audit of newly developed outreach clinics in Northern Ireland. Ophthalmic Physiol Opt 2004;24:360-368.

39. Puvanachandra N, Kang CY, Kirwan JF \& Jeffrey MN. How good are we at advising appropriate patients with glaucoma to inform the DVLA? A closed audit loop. Ophthalmic Physiol Opt 2008;28:313-316.

40. Keane PA, Patel PJ, Liakopoulos S, Heussen FM, Sadda SR \& Tufail A. Evaluation of age-related macular degeneration with optical coherence tomography. Surv Ophthalmol 2012;57:389-414.

41. Marsiglia M, Boddu S, Bearelly S, et al. Association between geographic atrophy progression and reticular pseudodrusen in eyes with dry age-related macular degeneration. Invest Ophthalmol Vis Sci 2013;54:7362-7369.

42. Wightman AJ \& Guymer RH. Reticular pseudodrusen: current understanding. Clin Exp Optom 2019;102:455-462.

43. Govendert, Ehrlich R, Van Vuuren U, et al. Clinical audit of diabetes management can improve the quality of care in a resource-limited primary care setting. Int J Qual Health Care 2012;24:612-618.

44. Han NW, Jamhuri N, Rahman ZA, Sharina B, Lai MH \& Samwil SN. Clinical audit on adherence to using Malnutrition Screening Tool and dietitian referral in the Oncology Outpatient Clinic, National Cancer Institute, Malaysia. Malays J Nutr 2018;24:627-635.

45. Esposito P \& Dal Canton A. Clinical audit, a valuable tool to improve quality of care: General methodology and applications in nephrology. World J Nephrol 2014;3:249255.

46. Mak DB \& Miflin B. Clinical audit in the final year of undergraduate medical education: towards better care of future generations. Med Teach 2012;34:e251e257.

47. Pessian F \& Beckett HA. Record keeping by undergraduate dental students: a clinical audit. Br Dent J 2004;197:703-705. 
48. Vijayakumar C, Maroju NK, Srinivasan K \& Reddy KS. Clinical audit system as a quality improvement tool in the management of breast cancer. Int J Surg 2016;35:44-50.

49. Sivertsen J, Graverholt B \& Espehaug B. Dysphagia screening after acute stroke: a quality improvement project using criteria-based clinical audit. BMC Nurs 2017;16:27.

50. McKay-Brown L, Bishop N, Balmford J, Borland R, Kirby C \& Piterman L. The impact of a GP clinical audit on the provision of smoking cessation advice. Asia Pac Fam Med 2008;7:4.

51. Azzolini E, Furia G, Cambieri A, Ricciardi W, Volpe M \& Poscia A. Quality improvement of medical records through internal auditing: a comparative analysis. $J$ Prev Med Hyg 2019;60:E250-E255.

52. Schmidt M, Rizvi N, Lee DM, Wood V, Amisano S \& Fairley CK. An audit of completeness of clinical histories: before and after introduction of a pro forma. Int J STD AIDS 2005;16:822-824.

53. Galor A \& Lee DJ. Effects of smoking on ocular health. Curr Opin Ophthalmol 2011;22:477-482.

54. Sayin N, Kara N, Pekel G \& Altinkaynak H. Effects of chronic smoking on central corneal thickness, endothelial cell, and dry eye parameters. Cutan Ocul Toxicol 2014;33:201-205.

55. Farzandipour M, Meidani Z, Rangraz Jeddi F, et al. A pilot study of the impact of an educational intervention aimed at improving medical record documentation. $J R$ Coll Physicians Edinb 2013;43:29-34.

56. Kleczka B, Musiega A, Rabut G et al. Rubber stamp templates for improving clinical documentation: A paper-based, m-Health approach for quality improvement in lowresource settings. Int J Med Inform 2018;114:121-129.

57. Weng J, Zhao J, Zhou Z et al. Observational study evaluating the effectiveness of physician-targeted education for improving glycemic management of patients with type 2 diabetes (BEYOND II). J Diabetes 2020;12:66-76.

58. Bowie P, Bradley NA \& Rushmer R. Clinical audit and quality improvement - time for a rethink? J Eval Clin Pract 2012;18:42-48.

59. Faes L, Bodmer NS, Bachmann LM, Thiel MA \& Schmid MK. Diagnostic accuracy of the Amsler grid and the preferential hyperacuity perimetry in the screening of 
patients with age-related macular degeneration: systematic review and metaanalysis. Eye (Lond) 2014;28:788-796.

60. Augustin AJ, Offermann I, Lutz J, Schmidt-Erfurth U \& Tornambe P. Comparison of the original Amsler grid with the modified Amsler grid: Results for patients with agerelated macular degeneration. Retina 2005;25:443-445.

61. Finger RP, Chong E, McGuinness MB, et al. Reticular Pseudodrusen and Their Association with Age-Related Macular Degeneration: The Melbourne Collaborative Cohort Study. Ophthalmology 2016;123:599-608.

62. Finger RP, Wu Z, Luu CD, et al. Reticular pseudodrusen: a risk factor for geographic atrophy in fellow eyes of individuals with unilateral choroidal neovascularization. Ophthalmology 2014;121:1252-1256.

63. Wu Z, Ayton LN, Luu CD, Baird PN \& Guymer RH. Reticular Pseudodrusen in Intermediate Age-Related Macular Degeneration: Prevalence, Detection, Clinical, Environmental, and Genetic Associations. Invest Ophthalmol Vis Sci 2016;57:13101316.

64. Keenan TD, Chen Q, Peng Y, et al. Deep learning automated detection of reticular pseudodrusen from fundus autofluorescence images or color fundus photographs in AREDS2. Ophthalmology 2020; doi: 10.1016/j.ophtha.2020.05.036, accessed 1/7/20

65. Lee MY, Yoon J \& Ham DI. Clinical features of reticular pseudodrusen according to the fundus distribution. Br J Ophthalmol 2012;96:1222-1226.

66. Fenner BJ, Wong RLM, Lam WC, Tan GSW \& Cheung GCM. Advances in Retinal Imaging and Applications in Diabetic Retinopathy Screening: A Review. Ophthalmol Ther 2018;7:333-346.

67. Lin DY, Blumenkranz MS, Brothers RJ \& Grosvenor DM. The sensitivity and specificity of single-field nonmydriatic monochromatic digital fundus photography with remote image interpretation for diabetic retinopathy screening: a comparison with ophthalmoscopy and standardized mydriatic color. Am J Ophthalmol 2002;134:204213.

68. Ku JJ, Landers J, Henderson T \& Craig JE. The reliability of single-field fundus photography in screening for diabetic retinopathy: the Central Australian Ocular Health Study. Med J Aust 2013;198:93-96. 
69. Pugh JA, Jacobson JM, Van Heuven WA, et al. Screening for diabetic retinopathy. The wide-angle retinal camera. Diabetes Care 1993;16:889-895.

70. Salti HI, Antonios RS, Haddad SS, Hamam RN, Bashshur ZF \& Ghazi NG. Combined Nonmydriatic Spectral-Domain Optical Coherence Tomography and Nonmydriatic Fundus Photography for the Detection of Age-Related Macular Degeneration Changes. Ophthalmic Surg Lasers Imaging Retina 2015;46:531-537.

71. Kirby CN, Piterman L \& Giles C. GP management of erectile dysfunction: The impact of clinical audit and guidelines. Aust Fam Physician 2009;38:637-641.

72. Palmer NA, Dailey YM \& Martin MV. Can audit improve antibiotic prescribing in general dental practice? Br Dent J 2001;191:253-255.

73. Valikodath NG, Newman-Casey PA, Lee PP, Musch DC, Niziol LM \& Woodward MA. Agreement of Ocular Symptom Reporting Between Patient-Reported Outcomes and Medical Records. JAMA Ophthalmol 2017;135:225-231.

74. Krebs EE, Bair MJ, Carey TS \& Weinberger M. Documentation of pain care processes does not accurately reflect pain management delivered in primary care. J Gen Intern Med 2010;25:194-199.

75. Lumbreras García G, Mena Ruiz MD, Calvo Álvarez I, et al. Prevalence of antismoking advice in a primary care center: comparison of the record in the medical record with that reported by the user. Arch Bronconeumol 2002;38:317-321.

76. McCambridge J, Witton J \& Elbourne DR. Systematic review of the Hawthorne effect: new concepts are needed to study research participation effects. J Clin Epidemiol 2014;67:267-277.

77. Dickson WJ \& Roethlisberger FJ. Counseling in an organization: A sequel to the Hawthorne researches. Division of Research, Graduate School of Business Administration, Harvard University; 1966.

78. Lord J \& Littlejohns P. Impact of Hospital and Community Provider Based Clinical Audit Programmes: Perceptions of Doctors, Nurses and Other Health Professionals. Int J Qual Health Care 1996;8:527-535.

79. Sealey C. Two Common Pitfalls in Clinical Audit: Failing to Complete the Audit Cycle and Confusing Audit with Research. Brit J Occup Ther 1999;62:238-243. 


\section{Supplementary materials}

\section{Appendix S1: Statistical analyses of parametric data, using Student's Paired t-test}

AMD: age-related macular degeneration; DFE: dilated retinal fundus examination; RPD: reticular pseudodrusen; SD: standard deviation

\begin{tabular}{|c|c|c|c|c|c|c|}
\hline Area assessed & Documented parameter & Audit period & $\begin{array}{l}\text { Mean } \\
(\%)\end{array}$ & SD (\%) & $\begin{array}{l}95 \% \\
\text { Confidence } \\
\text { interval }\end{array}$ & $\begin{array}{l}\text { Paired t- } \\
\text { test } \\
\text { outcome }\end{array}$ \\
\hline \multirow{12}{*}{$\begin{array}{l}\text { Demographics } \\
\text { and risk factor }\end{array}$} & \multirow[t]{2}{*}{ Ethnicity } & Pre-audit & 22 & 35 & $6-38$ & \multirow{2}{*}{$\begin{array}{c}t(19)=4.26 ; \\
p<0.01\end{array}$} \\
\hline & & Post-audit & 59 & 35 & $43-75$ & \\
\hline & \multirow{2}{*}{ Driving status } & Pre-audit & 60 & 39 & $42-78$ & \multirow{2}{*}{$\begin{array}{c}t(19)=3.30 ; \\
p<0.01\end{array}$} \\
\hline & & Post-audit & 78 & 26 & $66-90$ & \\
\hline & \multirow{2}{*}{ General practitioner details } & Pre-audit & 47 & 36 & $30-64$ & \multirow{2}{*}{$\begin{array}{c}t(19)=3.84 ; \\
p<0.01\end{array}$} \\
\hline & & Post-audit & 75 & 28 & $62-89$ & \\
\hline & \multirow{2}{*}{ Current dietary behaviours } & Pre-audit & 11 & 18 & $2-19$ & \multirow{2}{*}{$\begin{array}{c}t(19)=2.93 ; \\
p<0.01\end{array}$} \\
\hline & & Post-audit & 29 & 26 & $16-41$ & \\
\hline & \multirow{2}{*}{ Current smoking status } & Pre-audit & 21 & 32 & $6-36$ & \multirow{2}{*}{$\begin{array}{c}t(19)=5.51 ; \\
p<0.01\end{array}$} \\
\hline & & Post-audit & 58 & 33 & $43-74$ & \\
\hline & \multirow{2}{*}{$\begin{array}{l}\text { Current nutritional } \\
\text { supplementation intake }\end{array}$} & Pre-audit & 20 & 21 & $10-30$ & \multirow{2}{*}{$\begin{array}{c}t(19)=4.05 ; \\
p<0.01\end{array}$} \\
\hline & & Post-audit & 51 & 39 & $32-69$ & \\
\hline \multirow{10}{*}{$\begin{array}{l}\text { Clinical } \\
\text { Examination }\end{array}$} & \multirow{2}{*}{ Monocular pinhole acuities } & Pre-audit & 28 & 29 & $14-42$ & \multirow{2}{*}{$\begin{array}{c}t(19)=2.63 ; \\
p=0.02\end{array}$} \\
\hline & & Post-audit & 53 & 38 & $35-71$ & \\
\hline & \multirow{2}{*}{ Amsler grid test in-office } & Pre-audit & 28 & 29 & $14-42$ & \multirow{2}{*}{$\begin{array}{c}t(19)=2.63 ; \\
p=0.02\end{array}$} \\
\hline & & Post-audit & 53 & 38 & $35-71$ & \\
\hline & \multirow{2}{*}{ Dilated fundus examination } & Pre-audit & 34 & 30 & $19-48$ & \multirow{2}{*}{$\begin{array}{c}t(19)=1.26 ; \\
p=0.22\end{array}$} \\
\hline & & Post-audit & 40 & 24 & $29-52$ & \\
\hline & \multirow[t]{2}{*}{ Retinal imaging performed } & Pre-audit & 77 & 30 & $63-91$ & \multirow{2}{*}{$\begin{array}{c}t(19)=0.04 ; \\
p=0.97\end{array}$} \\
\hline & & Post-audit & 77 & 29 & $64-90$ & \\
\hline & \multirow[t]{2}{*}{ Fundus photography } & Pre-audit & 77 & 30 & $63-91$ & \multirow{2}{*}{$\begin{array}{c}t(19)=0.93 ; \\
p=0.36\end{array}$} \\
\hline & & Post-audit & 72 & 31 & $58-87$ & \\
\hline
\end{tabular}




\begin{tabular}{|c|c|c|c|c|c|c|}
\hline & \multirow{2}{*}{$\begin{array}{l}\text { Optical coherence } \\
\text { tomography (OCT) } \\
\text { performed }\end{array}$} & Pre-audit & 36 & 32 & $21-51$ & \multirow{2}{*}{$\begin{array}{c}t(19)=3.91 ; \\
p<0.01\end{array}$} \\
\hline & & Post-audit & 62 & 33 & $47-77$ & \\
\hline & \multirow{2}{*}{$\begin{array}{l}\text { Multimodal imaging } \\
\text { performed }\end{array}$} & Pre-audit & 36 & 38 & $18-54$ & \multirow{2}{*}{$\begin{array}{c}t(19)=0.72 ; \\
p=0.48\end{array}$} \\
\hline & & Post-audit & 41 & 38 & $23-59$ & \\
\hline & \multirow{2}{*}{$\begin{array}{l}\text { Imaging performed without } \\
\text { DFE }\end{array}$} & Pre-audit & 62 & 32 & $46-77$ & \multirow{2}{*}{$\begin{array}{c}t(18)=2.46 \\
p=0.02\end{array}$} \\
\hline & & Post-audit & 48 & 28 & $35-62$ & \\
\hline \multirow{6}{*}{$\begin{array}{l}\text { Classification } \\
\text { of AMD stage }\end{array}$} & \multirow{2}{*}{$\begin{array}{l}\text { Presence of reticular } \\
\text { pseudodrusen (RPD) }\end{array}$} & Pre-audit & 9 & 15 & $2-16$ & \multirow{2}{*}{$\begin{array}{l}t(19)=2.94 \\
p<0.01\end{array}$} \\
\hline & & Post-audit & 31 & 35 & $15-48$ & \\
\hline & \multirow{2}{*}{ Intermediate AMD } & Pre-audit & 62 & 40 & $42-83$ & \multirow{2}{*}{$\begin{array}{c}t(16)=1.52 ; \\
p=0.15\end{array}$} \\
\hline & & Post-audit & 82 & 33 & $65-99$ & \\
\hline & \multirow{2}{*}{ Late AMD } & Pre-audit & 68 & 30 & $51-85$ & \multirow{2}{*}{$\begin{array}{c}t(14)=2.13 \\
p=0.05\end{array}$} \\
\hline & & Post-audit & 80 & 30 & $63-96$ & \\
\hline \multirow{16}{*}{$\begin{array}{c}\text { AMD } \\
\text { management }\end{array}$} & \multirow{2}{*}{$\begin{array}{l}\text { Normal macula/normal } \\
\text { ageing changes: diet and } \\
\text { nutritional supplement } \\
\text { behaviours }\end{array}$} & Pre-audit & 22 & 27 & $9-35$ & \multirow{2}{*}{$\begin{array}{c}t(18)=3.44 ; \\
p<0.01\end{array}$} \\
\hline & & Post-audit & 50 & 44 & $29-71$ & \\
\hline & \multirow{2}{*}{$\begin{array}{l}\text { Early AMD: smoking } \\
\text { behaviours }\end{array}$} & Pre-audit & 30 & 39 & $0-60$ & \multirow{2}{*}{$\begin{array}{c}t(8)=3.41 ; \\
p<0.01\end{array}$} \\
\hline & & Post-audit & 85 & 24 & $67-100$ & \\
\hline & \multirow{2}{*}{$\begin{array}{l}\text { Early AMD: diet and } \\
\text { nutritional supplement } \\
\text { advice }\end{array}$} & Pre-audit & 36 & 45 & $1-71$ & \multirow{2}{*}{$\begin{array}{c}t(8)=2.91 \\
p=0.02\end{array}$} \\
\hline & & Post-audit & 89 & 24 & $71-100$ & \\
\hline & \multirow{2}{*}{$\begin{array}{l}\text { Early AMD: Amsler grid } \\
\text { provision }\end{array}$} & Pre-audit & 33 & 43 & $0-66$ & \multirow{2}{*}{$\begin{array}{c}t(8)=1.67 ; \\
p=0.13\end{array}$} \\
\hline & & Post-audit & 67 & 42 & $35-100$ & \\
\hline & \multirow{2}{*}{$\begin{array}{l}\text { Early AMD: Amsler grid } \\
\text { weekly monitoring } \\
\text { instructions }\end{array}$} & Pre-audit & 27 & 36 & $0-54$ & \multirow{2}{*}{$\begin{array}{c}t(8)=0.77 \\
p=0.46\end{array}$} \\
\hline & & Post-audit & 42 & 49 & $4-79$ & \\
\hline & \multirow{2}{*}{$\begin{array}{l}\text { Intermediate AMD: diet and } \\
\text { nutritional supplement } \\
\text { advice }\end{array}$} & Pre-audit & 45 & 47 & $17-74$ & \multirow{2}{*}{$\begin{array}{c}t(12)=2.22 \\
p=0.046\end{array}$} \\
\hline & & Post-audit & 80 & 34 & $60-100$ & \\
\hline & \multirow{2}{*}{$\begin{array}{l}\text { Intermediate AMD: risk of } \\
\text { AMD progression }\end{array}$} & Pre-audit & 12 & 26 & $0-28$ & \multirow{2}{*}{$\begin{array}{c}t(12)=1.06 \\
p=0.31\end{array}$} \\
\hline & & Post-audit & 25 & 39 & $1-48$ & \\
\hline & \multirow{2}{*}{$\begin{array}{l}\text { Intermediate AMD: Amsler } \\
\text { grid provision }\end{array}$} & Pre-audit & 43 & 44 & $16-70$ & \multirow{2}{*}{$\begin{array}{c}t(12)=3.52 ; \\
p<0.01\end{array}$} \\
\hline & & Post-audit & 84 & 20 & $72-96$ & \\
\hline
\end{tabular}

This article is protected by copyright. All rights reserved 


\begin{tabular}{|c|c|c|c|c|c|c|}
\hline & \multirow{2}{*}{$\begin{array}{l}\text { Intermediate AMD: Amsler } \\
\text { grid weekly home } \\
\text { monitoring instructions }\end{array}$} & Pre-audit & 30 & 32 & $11-50$ & \multirow{2}{*}{$\begin{array}{l}t(12)=3.70 ; \\
p<0.01\end{array}$} \\
\hline & & Post-audit & 69 & 37 & $46-91$ & \\
\hline \multirow{10}{*}{$\begin{array}{c}\text { Area for } \\
\text { improvement }\end{array}$} & \multirow{2}{*}{ Current dietary behaviours } & Pre-audit & 12 & 21 & $0-26$ & \multirow{2}{*}{$\begin{array}{c}t(11)=1.67 \\
p=0.12\end{array}$} \\
\hline & & Post-audit & 26 & 22 & $12-40$ & \\
\hline & \multirow{2}{*}{ Amsler grid test in-office } & Pre-audit & 16 & 20 & $2-29$ & \multirow{2}{*}{$\begin{array}{c}t(10)=2.67 \\
p=0.02\end{array}$} \\
\hline & & Post-audit & 55 & 40 & $28-82$ & \\
\hline & \multirow{2}{*}{ Stereoscopic examination } & Pre-audit & 36 & 50 & $0-88$ & \multirow{2}{*}{$\begin{array}{c}t(5)=1.84 ; \\
p=0.13\end{array}$} \\
\hline & & Post-audit & 73 & 37 & $34-100$ & \\
\hline & \multirow{2}{*}{ Current smoking status } & Pre-audit & 15 & 27 & $2-29$ & \multirow{2}{*}{$\begin{array}{c}t(17)=5.28 \\
p<0.01\end{array}$} \\
\hline & & Post-audit & 54 & 32 & $38-69$ & \\
\hline & \multirow{2}{*}{ RPD documentation } & Pre-audit & 9 & 16 & $0-21$ & \multirow{2}{*}{$\begin{array}{c}t(8)=4.17 \\
p<0.01\end{array}$} \\
\hline & & Post-audit & 47 & 37 & $19-76$ & \\
\hline
\end{tabular}

\section{Appendix S2: Statistical analyses of non-parametric data, using Wilcoxon Test}

AMD: age-related macular degeneration; m: months; $n$ : number of participants

\begin{tabular}{|c|c|c|c|c|c|c|}
\hline Area assessed & $\begin{array}{l}\text { Documented } \\
\text { parameter }\end{array}$ & $\mathrm{n}$ & $\begin{array}{l}\text { Audit } \\
\text { period }\end{array}$ & $\begin{array}{c}\text { Median } \\
\text { (\%) }\end{array}$ & $\begin{array}{l}25^{\text {th }}-75^{\text {th }} \\
\text { Percentile (\%) }\end{array}$ & $P$ value \\
\hline \multirow{4}{*}{$\begin{array}{c}\text { Demographics } \\
\text { and risk factor } \\
\text { analysis }\end{array}$} & \multirow{2}{*}{$\begin{array}{l}\text { Family history of } \\
\text { AMD }\end{array}$} & 20 & Pre-audit & 94 & $77-100$ & \multirow[t]{2}{*}{0.03} \\
\hline & & 20 & Post-audit & 100 & $91-100$ & \\
\hline & \multirow[t]{2}{*}{ Medical history } & 20 & Pre-audit & 100 & $91-100$ & \multirow[t]{2}{*}{0.06} \\
\hline & & 20 & Post-audit & 100 & $100-100$ & \\
\hline & Monocular visual & 20 & Pre-audit & 100 & $97-100$ & 0.44 \\
\hline
\end{tabular}

This article is protected by copyright. All rights reserved 


\begin{tabular}{|c|c|c|c|c|c|c|}
\hline \multirow{3}{*}{$\begin{array}{c}\text { Clinical } \\
\text { Examination }\end{array}$} & acuities & 20 & Post-audit & 100 & $100-100$ & \multirow{3}{*}{0.38} \\
\hline & \multirow{2}{*}{$\begin{array}{l}\text { Posterior eye } \\
\text { examination }\end{array}$} & 20 & Pre-audit & 100 & $100-100$ & \\
\hline & & 20 & Post-audit & 100 & $100-100$ & \\
\hline & \multirow{2}{*}{$\begin{array}{l}\text { Bilateral posterior } \\
\text { eye examination }\end{array}$} & 20 & Pre-audit & 100 & $100-100$ & \multirow[t]{2}{*}{0.31} \\
\hline & & 20 & Post-audit & 100 & $100-100$ & \\
\hline \multirow{4}{*}{$\begin{array}{l}\text { Classification } \\
\text { of AMD stage }\end{array}$} & \multirow{2}{*}{$\begin{array}{l}\text { Normal macula } \\
\text { or normal ageing } \\
\text { changes }\end{array}$} & 20 & Pre-audit & 80 & $31-100$ & \multirow[t]{2}{*}{$<0.01$} \\
\hline & & 20 & Post-audit & 100 & $100-100$ & \\
\hline & \multirow{2}{*}{ Early AMD } & 11 & Pre-audit & 92 & $25-100$ & \multirow[t]{2}{*}{0.03} \\
\hline & & 11 & Post-audit & 100 & $100-100$ & \\
\hline \multirow{12}{*}{ management } & \multirow{2}{*}{$\begin{array}{l}\text { Normal } \\
\text { macula/normal } \\
\text { ageing changes: } \\
\text { smoking } \\
\text { behaviours }\end{array}$} & 19 & Pre-audit & 0 & $0-44$ & \multirow[t]{2}{*}{$<0.01$} \\
\hline & & 19 & Post-audit & 67 & $33-100$ & \\
\hline & \multirow{2}{*}{$\begin{array}{l}\text { Normal } \\
\text { macula/normal } \\
\text { ageing changes: }\end{array}$} & 19 & Pre-audit & 100 & $100-100$ & \multirow[t]{2}{*}{0.99} \\
\hline & & 19 & Post-audit & 100 & $100-100$ & \\
\hline & \multirow{2}{*}{$\begin{array}{l}\text { Early AMD: risk of } \\
\text { progression }\end{array}$} & 9 & Pre-audit & 0 & $0-37$ & \multirow[t]{2}{*}{0.99} \\
\hline & & 9 & Post-audit & 0 & $0-16$ & \\
\hline & \multirow{2}{*}{$\begin{array}{l}\text { Early AMD: } \\
\text { Review in } 12 \mathrm{~m}\end{array}$} & 9 & Pre-audit & 100 & $100-100$ & \multirow[t]{2}{*}{0.99} \\
\hline & & 9 & Post-audit & 100 & $100-100$ & \\
\hline & \multirow{2}{*}{$\begin{array}{l}\text { Intermediate } \\
\text { AMD: smoking } \\
\text { behaviours }\end{array}$} & 13 & Pre-audit & 0 & $0-63$ & \multirow[t]{2}{*}{$<0.01$} \\
\hline & & 13 & Post-audit & 100 & $53-100$ & \\
\hline & \multirow{2}{*}{$\begin{array}{l}\text { Intermediate } \\
\text { AMD: Review in } \\
6-12 \mathrm{~m}\end{array}$} & 13 & Pre-audit & 100 & $100-100$ & \multirow{2}{*}{0.99} \\
\hline & & & & & & \\
\hline
\end{tabular}



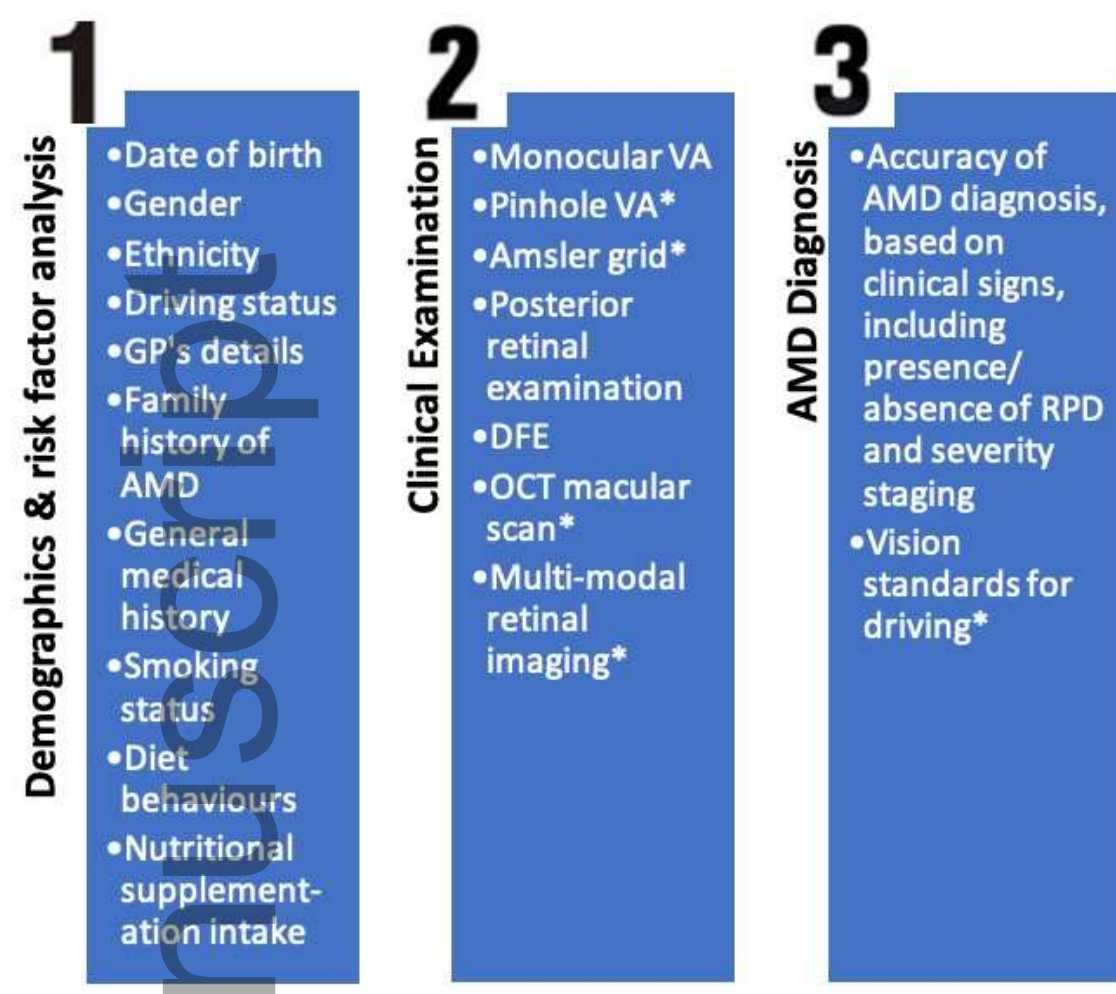

opo_12754_f1.tif

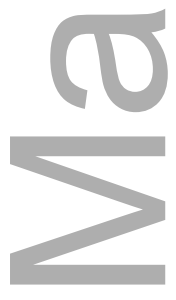

드-Smoking

ฮั behaviour

엉 advice*

-Diet \& nutritional

तั supplement

$\sum$ advice

을 -Appropriate

$\sum$ review period

-Risk of AMD

progression

- Provision of

Amsler grid for self-monitoring*

- Low vision

services*

-Ophthalmologist referral*

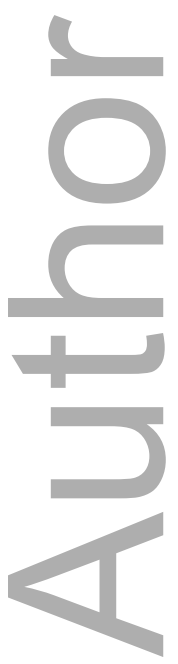




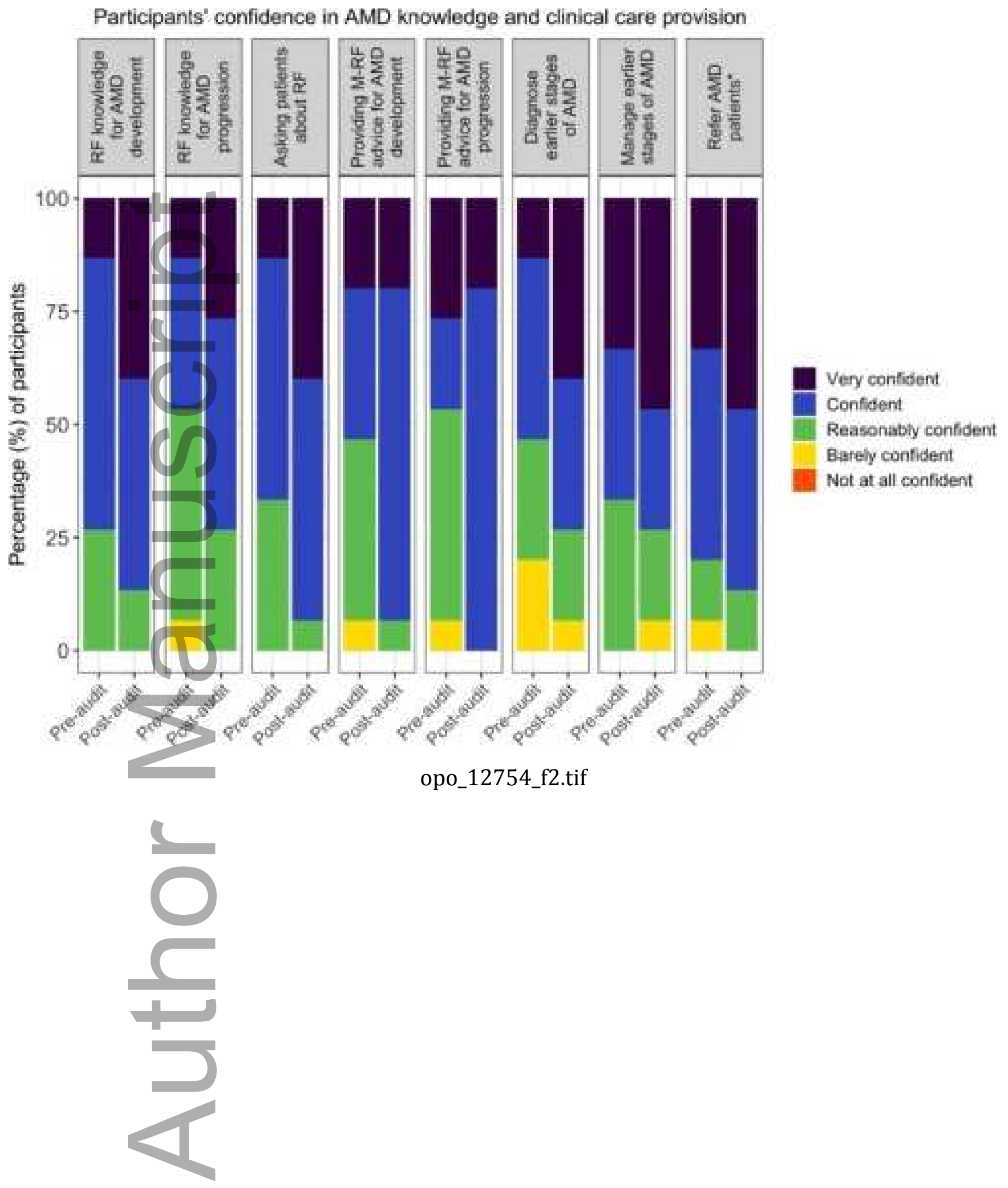


A

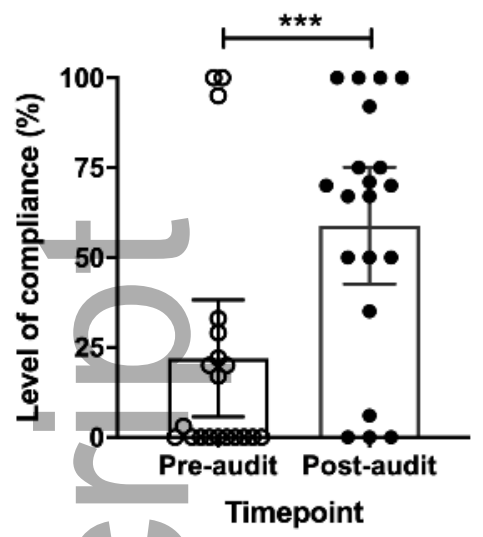

C General Practitioner details

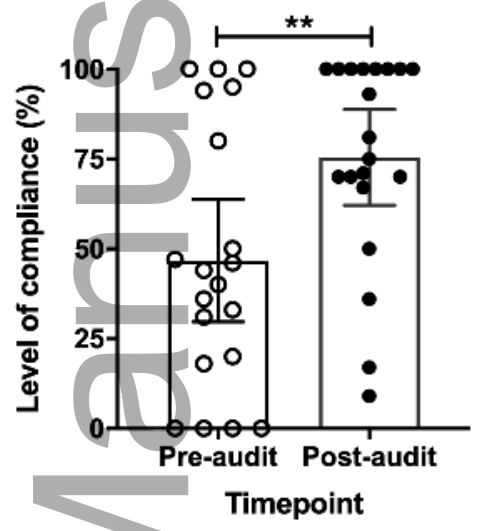

E Family history of $\mathrm{AMD}^{\dagger}$

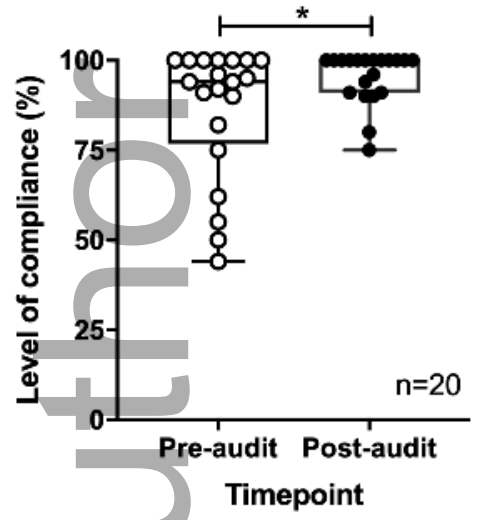

G Current dietary behaviours

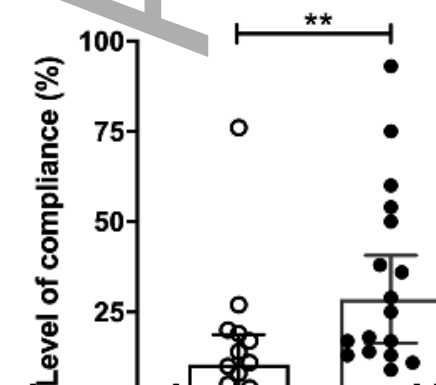

This artectight. All rights Pre-audit Post-audit

Timepoint
B Driving status

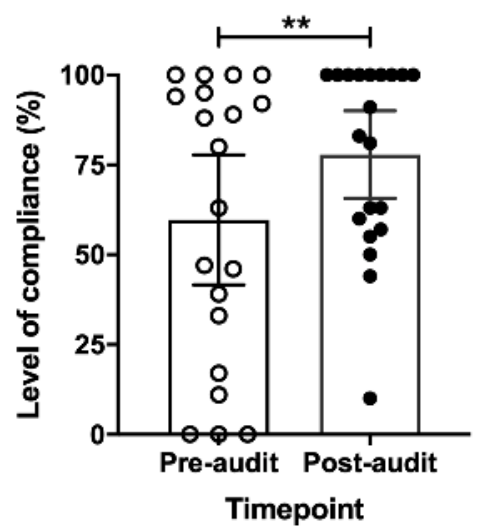

D Medical history ${ }^{\dagger}$

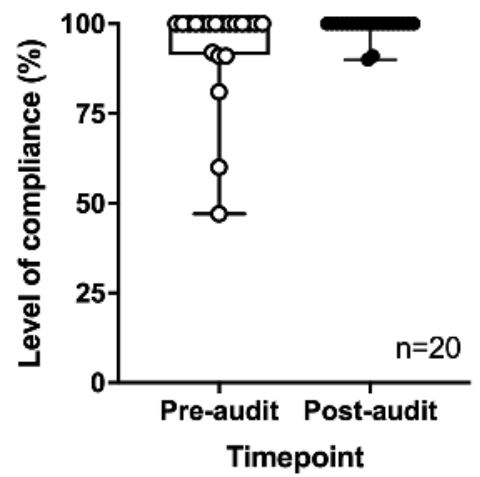

F Current smoking status

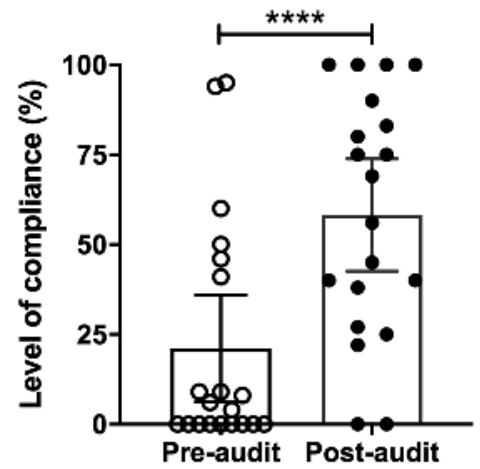

Timepoint

H Current nutritional supplement intake

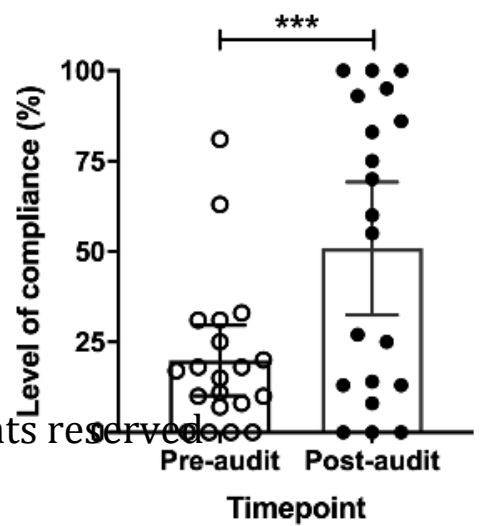




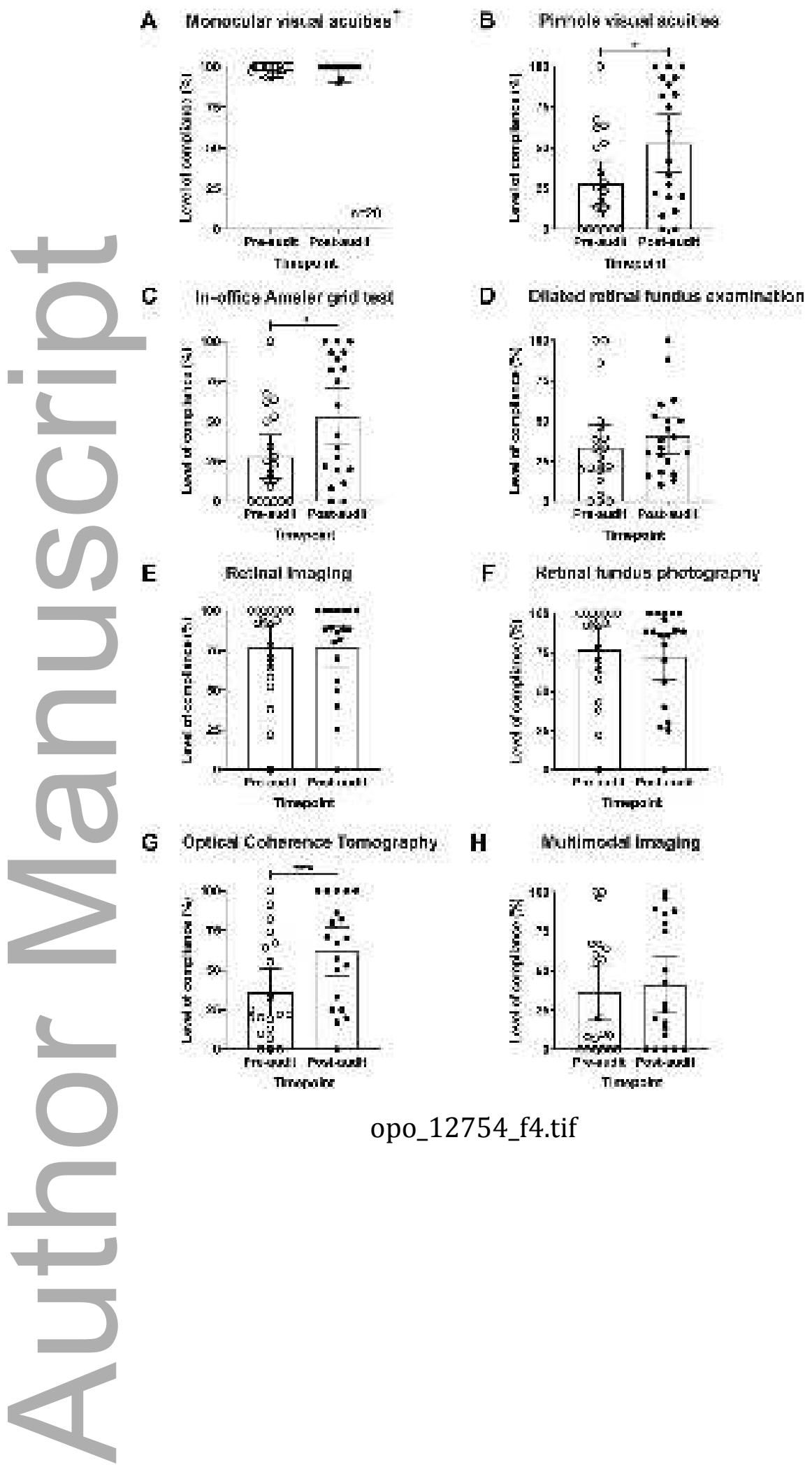

This article is protected by copyright. All rights reserved 
A Reticular pseudodrusen

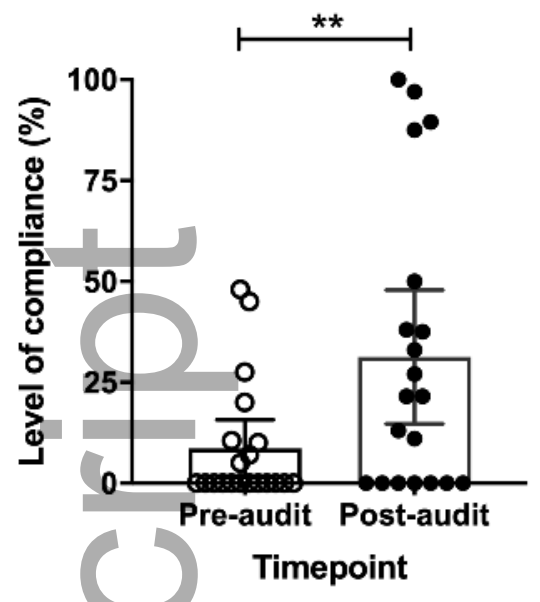

C Early AMD documented ${ }^{\dagger}$

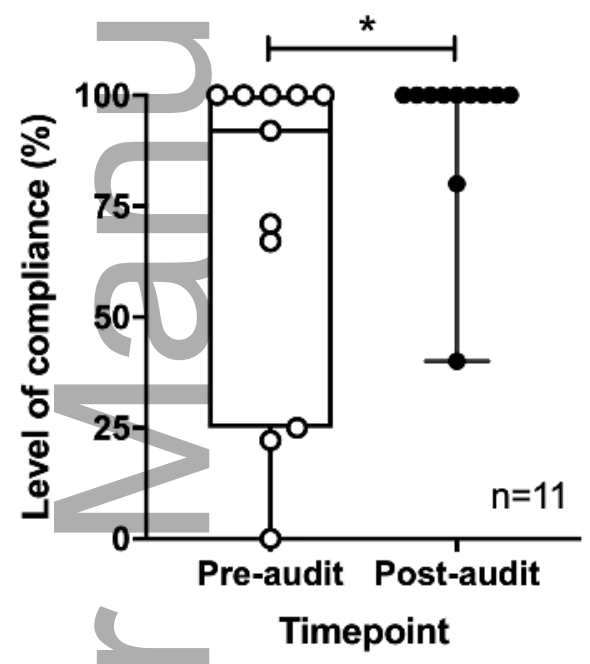

E Late AMD documented

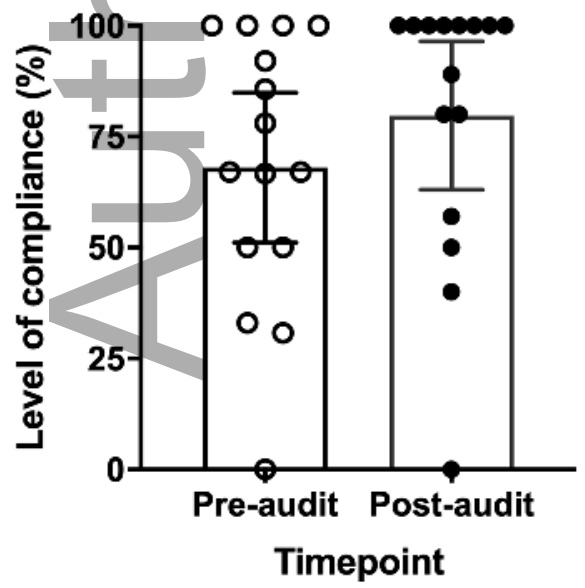

B Normal macula/ageing documented ${ }^{\dagger}$

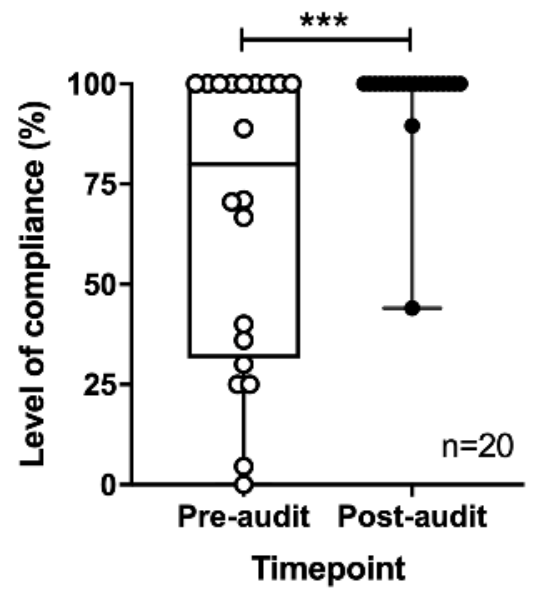

D Intermediate AMD documented

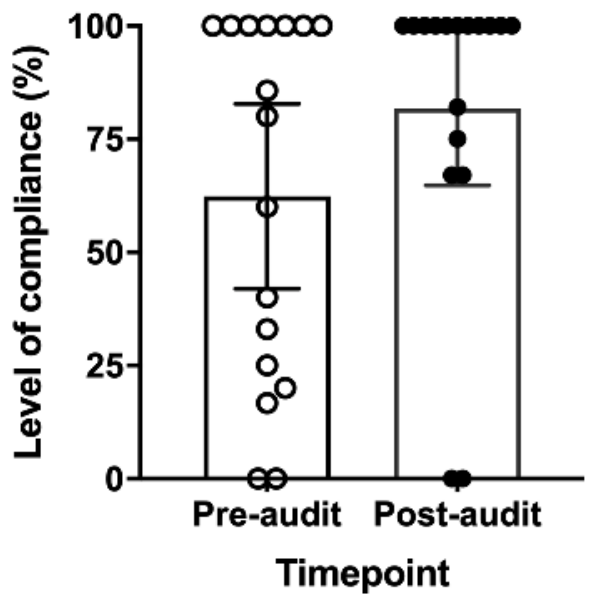




\section{Normal maculae/Normal Ageing Changes Management}

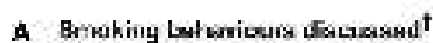
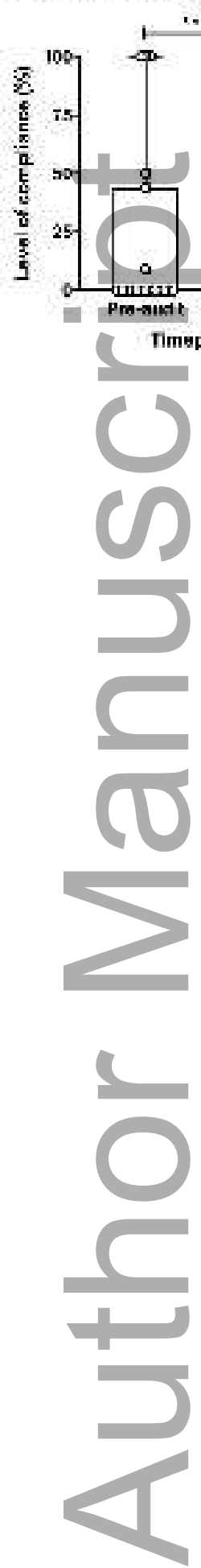

B Diet'unatritional sapsiarentation

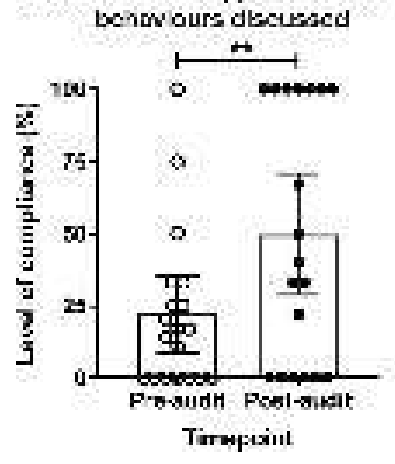

opo_12754_f6.tif

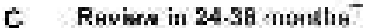

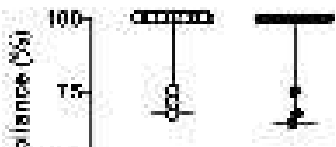

Pro-3inte Poetiont

Timepoint 


\section{Early AMD Management}

A Smoking behaviours discussed

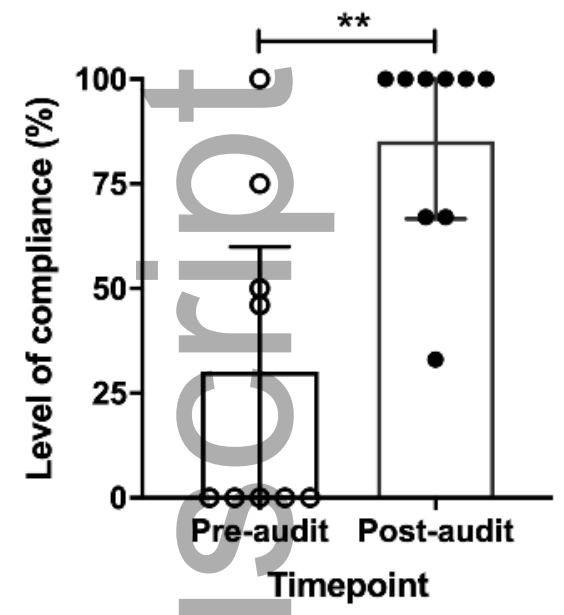

C Risk of AMD progression discussed ${ }^{\dagger}$

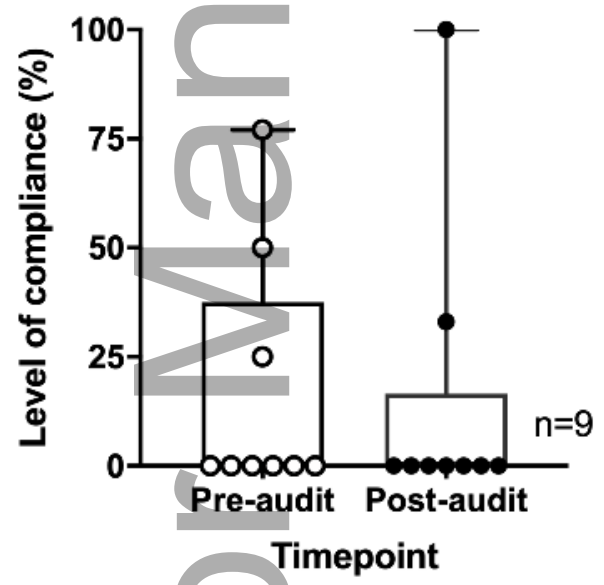

E Weekly monitoring instructions using Amsler grid

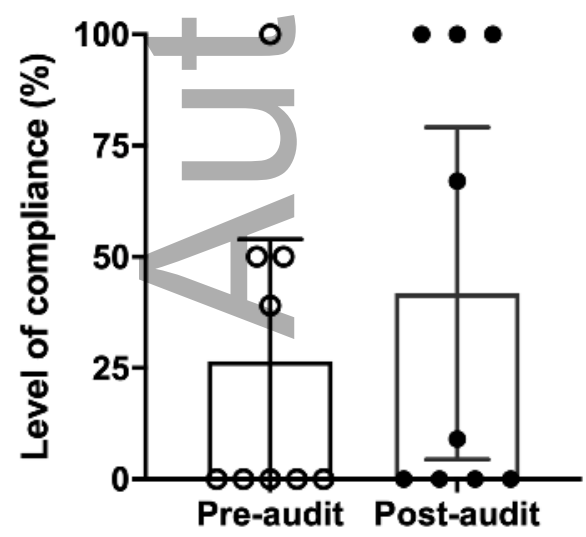

Timepoint
B Diet/nutritional supplementation behaviours discussed

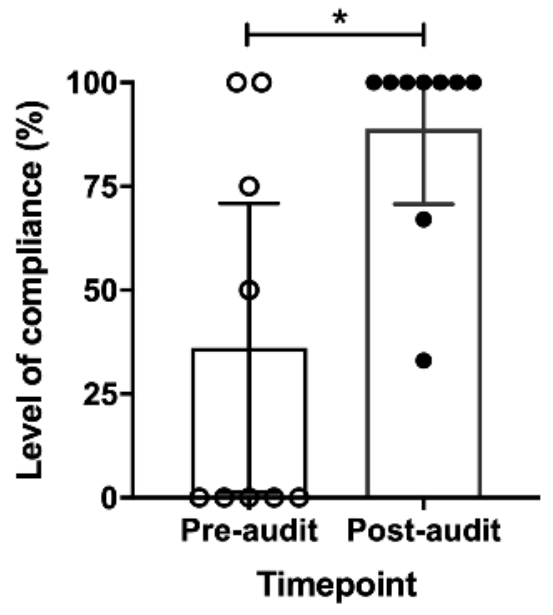

D Amsler grid provision for home monitoring

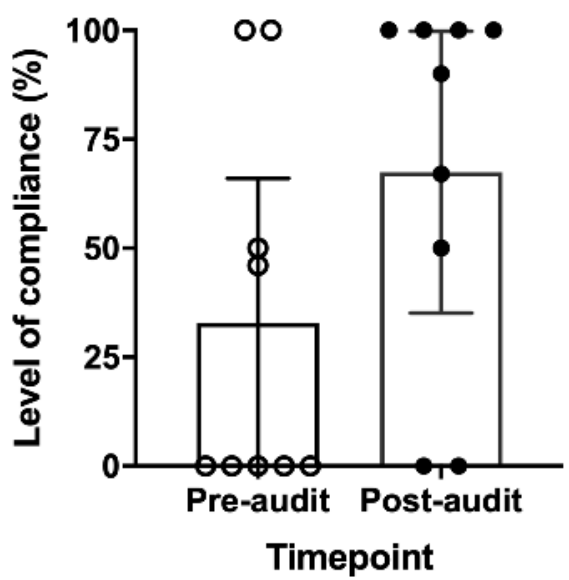

$\mathbf{F}$

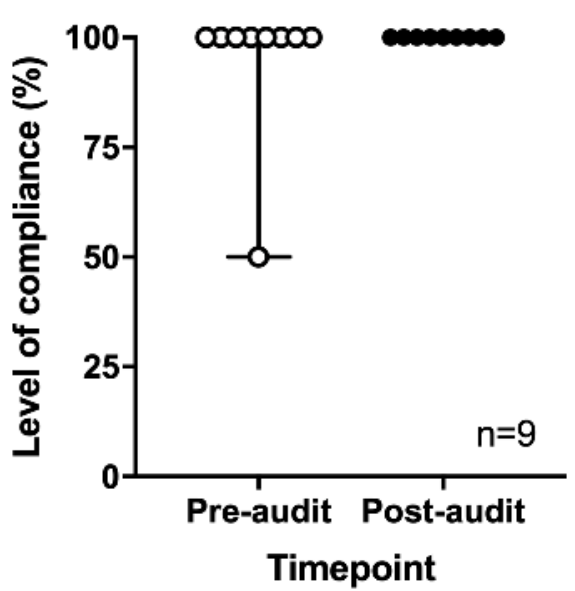

This article is protected by copyoight 1 dity 5 ilghitstifeserved 


\section{Intermediate AMD management}

A Smoking behaviours discussed ${ }^{\dagger}$

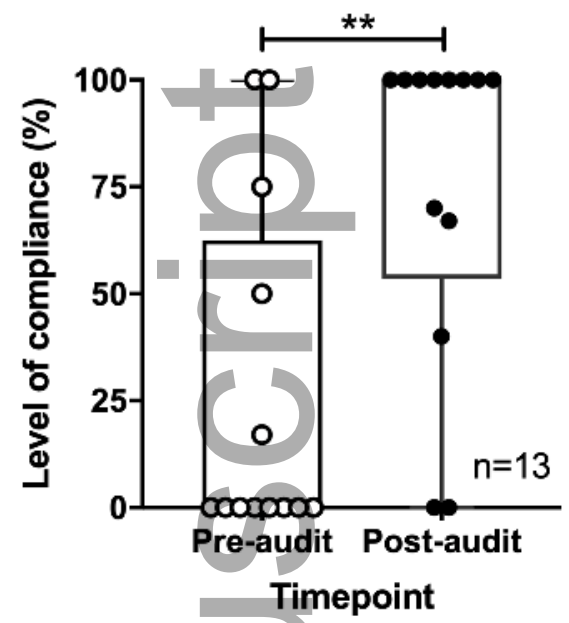

C Risk of AMD progression discussed

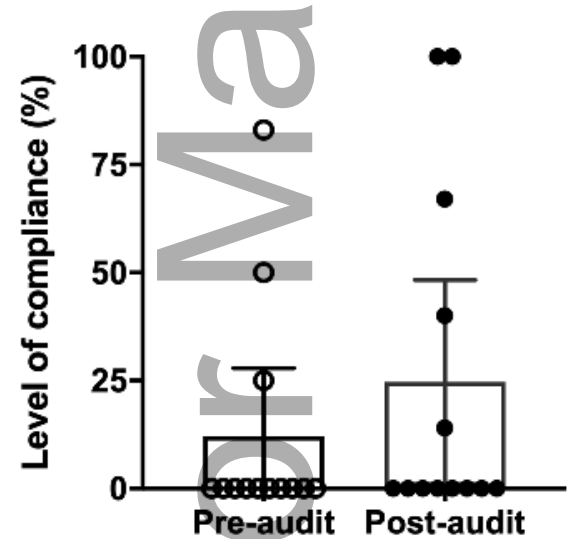

Timepoint

E Weekly monitoring instructions using Amsler grid

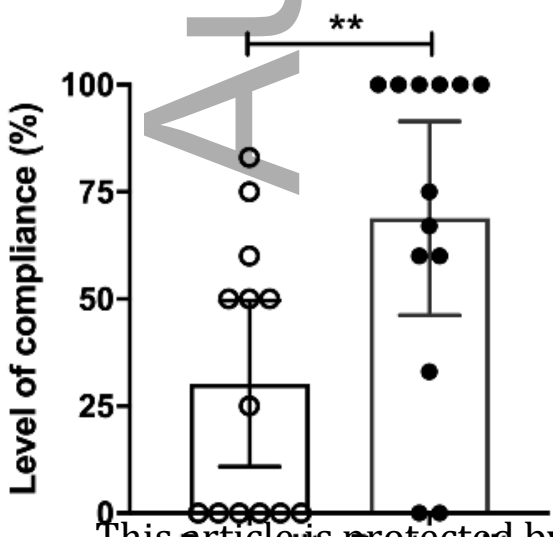

This artidedits prostequal by copyright. All rights reserved Pre-audit Post-audit
B Diet/nutritional supplementation behaviours discussed

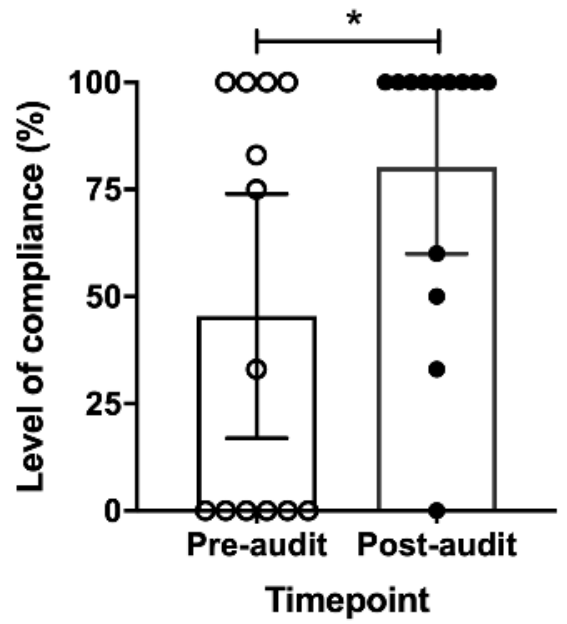

D Amsler grid provision for home monitoring

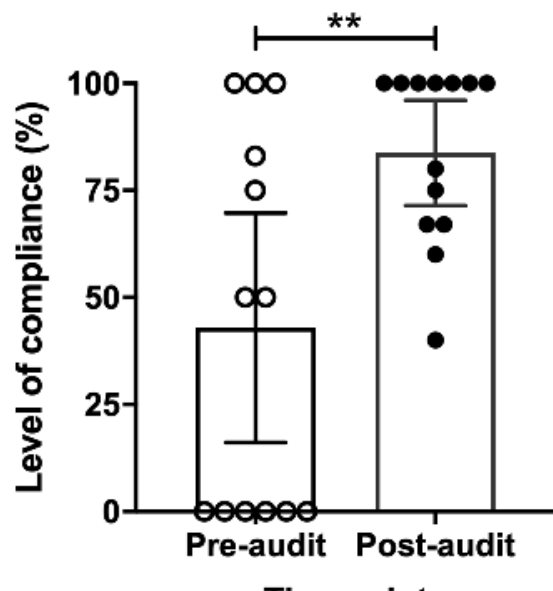

Timepoint

$\mathbf{F}$

Review in 6-12 months ${ }^{\dagger}$

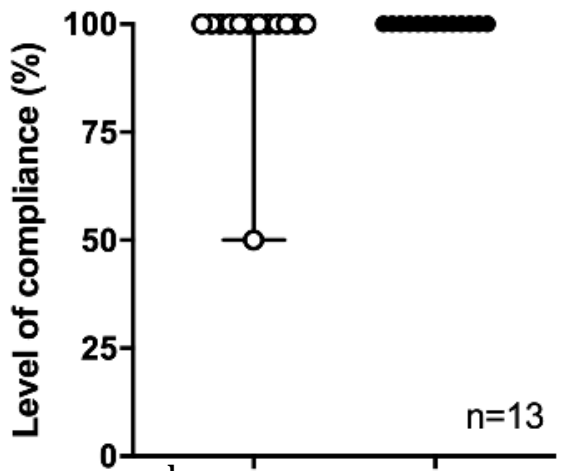

Timepoint 


\section{Area for improvement}

A Current smoking status

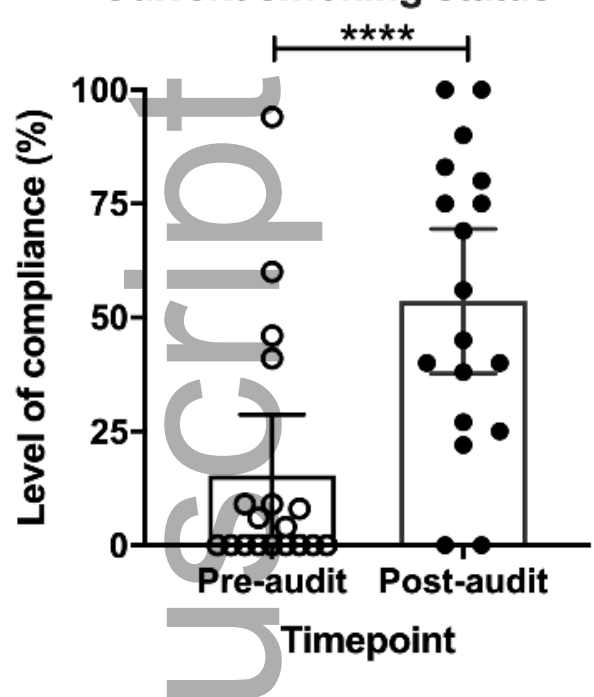

C In-office Amsler grid test



B Current dietary behaviours

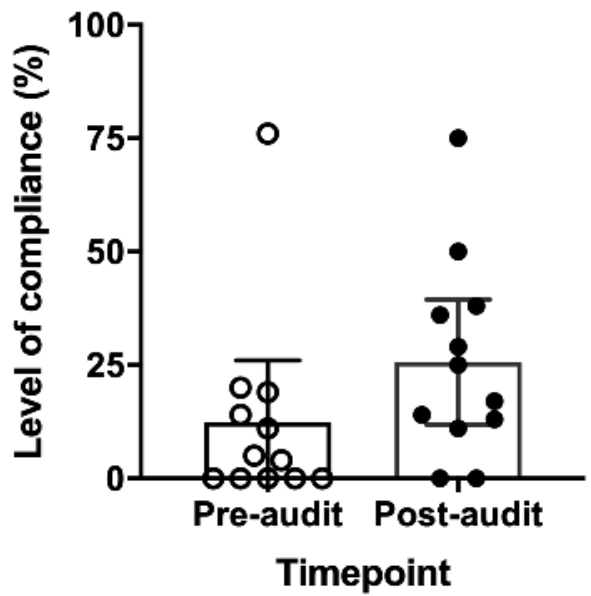

D RPD assessment

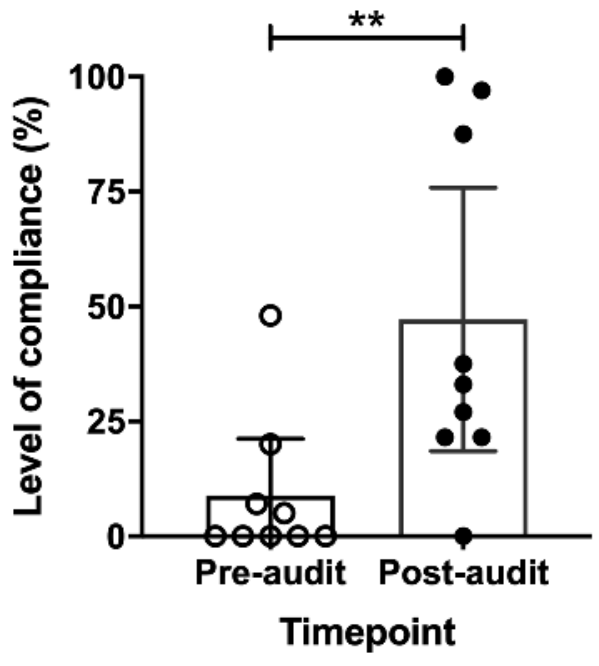

opo_12754_f9.tif 


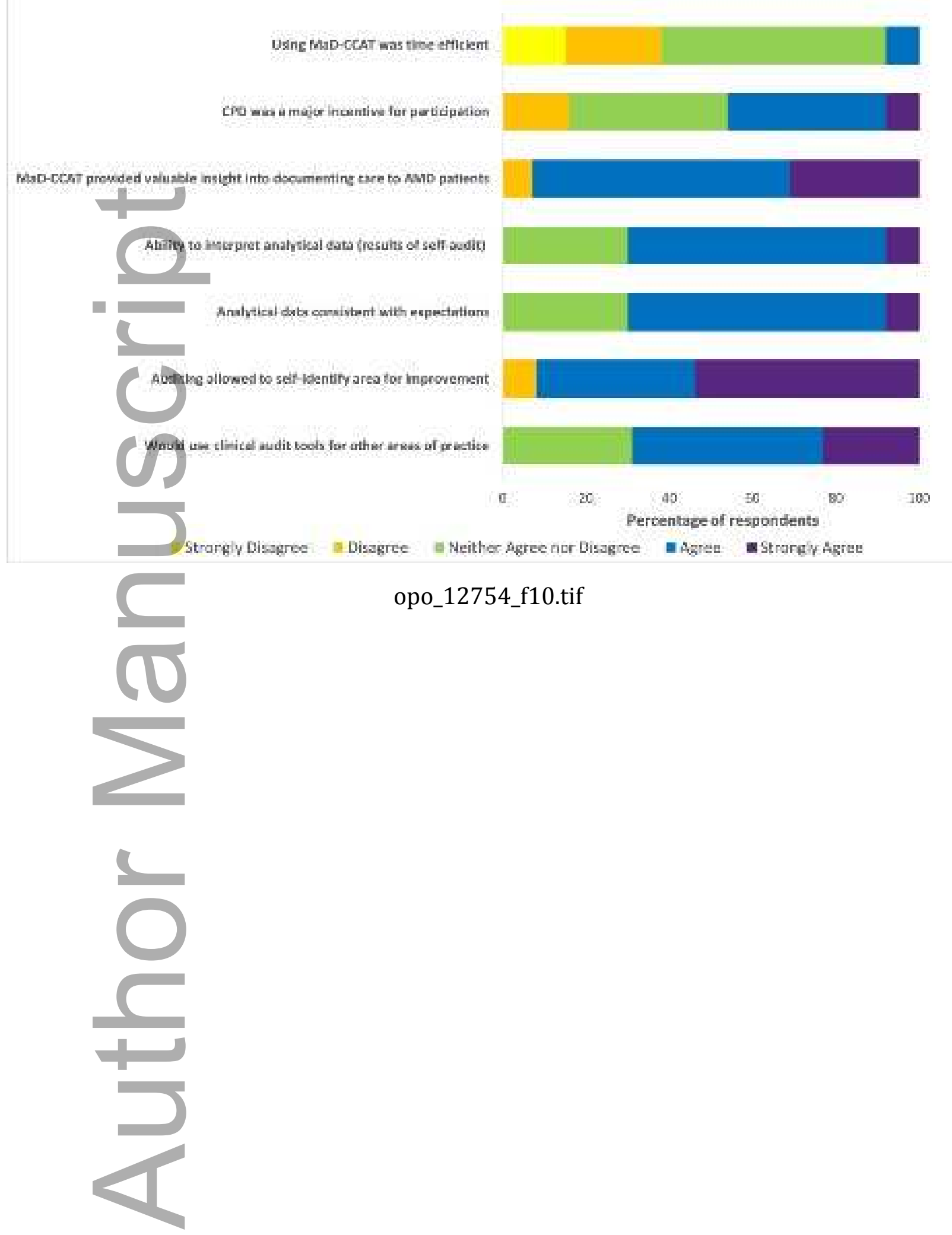

This article is protected by copyright. All rights reserved 


\section{University Library}

\section{- M M N E R VA A gateway to Melbourne's research publications}

Minerva Access is the Institutional Repository of The University of Melbourne

Author/s:

Gocuk, SA;Lee, J-H;Keller, PR;Ayton, LN;Guymer, RH;McKendrick, AM;Downie, LE

Title:

Clinical audit as an educative tool for optometrists: an intervention study in age-related macular degeneration

Date:

2021-01

\section{Citation:}

Gocuk, S. A., Lee, J. -H., Keller, P. R., Ayton, L. N., Guymer, R. H., McKendrick, A. M. \& Downie, L. E. (2021). Clinical audit as an educative tool for optometrists: an intervention study in age-related macular degeneration. OPHTHALMIC AND PHYSIOLOGICAL OPTICS, 41 (1), pp.53-72. https://doi.org/10.1111/opo.12754.

Persistent Link:

http://hdl.handle.net/11343/276578 